\title{
Miguel Mai y Antonio Sebastiano Minturno en la corte de Carlos V
}

\author{
Joan Bellsolell Martínez \\ Universitat de Girona \\ joan.bellsolell@udg.edu
}

Fecha de recepción: 18/12/2010, Fecha de publicación: 30/12/2010

<URL: http://www.studiaaurea.com/articulo.php?id=159>

\begin{abstract}
Resumen
El presente estudio es solo una muestra más de las múltiples formas en que la cultura renacentista italiana penetró en la corte del Emperador Carlos $\mathrm{V} y$, a través de ella, en los reinos hispánicos. El ejemplo que presentamos es un caso desconocido hasta hoy pues nunca se había puesto en relación a personajes como Miguel Mai, Canciller del Emperador, y a Antonio Sebastiano Minturno, obispo y humanista destacado de la primera mitad del siglo Xvi napolitano. A través del epistolario de ambos tratamos de reconstruir algunos detalles de los días en que la corte imperial visitó la ciudad de Nápoles, a finales de 1535 y principios de 1536
\end{abstract}

\section{Palabras clave}

Arte renacentista, epistolario, corte imperial, Poggioreale, Nápoles, Minturno, Miguel Mai, patrocinio cultural.

\begin{abstract}
Miguel Mai and Antonio Sebastiano Minturno at the Court of Charles V

This text is about how the Italian renaissance cultural world had in Carlos V emperor court a way where to get into Hispanic Kingdoms. The example presented here is unknown case until today because had never been related to the characters of Miguel Blai, Emperor's chancellor, with Antonio Sebastiano Minturno, a prominent humanist bishop of the first half of the seventeenth century Neapolitan. Through collected letters between both establish a better context of the past days spent by the imperial court in the city of Naples during 1535 and 1536.
\end{abstract}

\section{Key words}

Renaissance art, collected letters, imperial court, Poggioreale, Minturno, Miguel Mai, cultural patronage. 
El barcelonés Miguel Mai pertenecía a una casta originaria de Tremp que estuvo largos años al servicio de la monarquía: su abuelo, Joan Mai, formó parte de los Consejos Reales de Alfonso el Magnánimo y de Juan II; su padre, de idéntico nombre, del de Juan II y Fernando el Católico, monarcas que solían viajar con sus séquitos por territorios peninsulares e italianos. ${ }^{1}$ Es este componente cosmopolita el que hacía valiosos a los consejeros catalano-aragoneses, cuya visión del conjunto de los territorios nunca desatendía las particularidades locales. Miguel Mai era, además, un jurista adinerado que, fiel seguidor del erasmismo, hacía gala de notables inquietudes culturales y artísticas. ${ }^{2}$

Su posición privilegiada le llevó a acumular un cursus honorum que muy pocos lograrían. Todavía en época de Fernando el Católico se estrenó como Canciller del Reino de Cerdeña entre 1512 y 1520, poco antes de ingresar en la corte como Regente del Consejo de Aragón. Desde 1520 hasta 1528 perteneció al Consejo Real, lo que le obligó a viajar por toda Europa para asistir a acontecimientos culminantes como la coronación imperial en Aquisgrán (donde él mismo fue nombrado caballero), a visitar la Inglaterra de Enrique VIII y Catalina de Aragón, y presenciar la boda sevillana del Emperador. En julio de 1528, Mai fue nombrado titular de la embajada imperial en Roma, cargo que ocupó hasta febrero de 1533. A lo largo de esos cinco años su objetivo primordial fue restablecer las relaciones entre el Vaticano y el Emperador tras los aciagos acontecimientos del Sacco de 1527. También se encargó de negociar con Clemente VII las condiciones para el acceso de Carlos $\mathrm{V}$ a la corona imperial, cuya ceremonia en Bolonia se encargó de arbitrar, y, finalmente, defendió los intereses de la reina Catalina de Aragón en su divorcio de Enrique VIII. En 1533 fue nombrado Vicecanciller del Consejo Supremo de Aragón, puesto de la máxima responsabilidad, que solo tenía por encima al monarca. A partir de 1543 com-

1. El presente trabajo se enmarca en la labor desarrollada por parte del proyecto HAR200914149-C02-01 (subprograma ARTE), «Recepción del arte barroco en Cataluña (1640-1808). Fortuna historiográfica y vicisitudes patrimoniales», financiado por el Ministerio de Ciencia e Innovación. Así mismo supone una revisión de uno de los capítulos de mi tesis doctoral, Miquel Mai (c.1480-1546). Art i cultura a la cort de Carles $V$. Agradezco aquí la oportunidad que me ha brindado de publicar este trabajo la revista Studia Aurea, y especialmente agradezco a Eugenia Fosalba sus opiniones y consejos, imprescindibles para llegar al texto definitivo.

2. Hay varios estudios que tratan acerca de aspectos culturales de la primera mitad del siglo XVI que se ocupan del personaje de Miquel Mai pero no llegan a desarrollar su biografía. El texto más destacado sobre él es de Duran i Sanpere (1960), y trata de la herencia material y artística que dejó en Barcelona. Para un seguimiento de los viajes que realizó a lo largo de los años, Voltes Bou (1958). Sobre las relaciones en el mundo de la cultura librera barcelonesa y los estudios universitarios de la misma ciudad, Rubió i Balaguer (1973) y Batllori (1995). También puede consultarse a Moles (1990) para establecer una breve cronología. Finalmente, los vínculos entre Mai y el erasmismo fueron tratados por Bataillon (1983). Más recientes son mis trabajos, Bellsolell (2009, inédito) y Bellsolell (2011, inédito), en los que se edita la documentación conocida hasta este momento sobre Mai y se realiza un estudio y comentario sobre su biografía y sus relaciones con el mundo del arte y la cultura en general en el contexto de la corte de Carlos V. 
binará este cargo con el de Consejero del futuro Felipe II, aunque esta última dignidad solo podrá sobrellevarla hasta junio de 1546, fecha de su muerte.

No es de extrañar, así, que Miguel Mai fuera cortejado por numerosos artistas que deseaban abrirse camino en la corte. En la década de 1530 y los primeros años de 1540, y más especialmente en 1536, Miguel Mai estará en el centro de las relaciones culturales de las ciudades de Roma, Nápoles, Mesina y Génova. Desde 1512 a 1546, apenas llegará a permanecer tres años en su residencia barcelonesa, lo que nos da la medida de su cosmopolitismo. Cerca de quince años de este período los vivió en Italia.

La visita de la corte imperial a Italia durante los primeros meses 1536 constituye un despliegue cultural de tal intensidad que lo que vamos a intentar mostrar aquí no es más que la punta del iceberg. No es casual que los intereses cruzados que vayan aflorando confluyan en la figura de un erasmista italianizado procedente de Barcelona. La estrecha relación entre Italia y la Corona de Aragón tendrá en el campo artístico una forma de expresión muy visible, en forma de obras de arte importadas por los principales hombres de estado del momento. ${ }^{3}$ Miguel Mai fue un fino coleccionista de arte a lo largo de estos años, gracias a su posición social privilegiada y a su excelente formación humanista.

\section{Medallones, esculturas, pinturas, tapices y libros. Su documentación}

El nombre de Miguel Mai siempre se ha vinculado a dos aspectos de la historia barcelonesa de la primera mitad del siglo xvi: por un lado, se le ha relacionado con la historia del coleccionismo artístico gracias a un conjunto escultórico que guardó en su residencia de la céntrica Plaza de la Cucurulla de Barcelona, ${ }^{4}$ patrimonio que hoy se conserva en varias instituciones públicas y residencias privadas. A esta colección artística nos referiremos en breve. En segundo lugar, a Miguel Mai se le conoce por su acceso a cierta élite cultural del cenáculo erasmista de la ciudad, con personajes como el obispo Pedro de Cardona y Martin Ivarra. Quizá por su faceta erasmista y por su cargo político, a Mai también se le ha vinculado con los círculos literarios que orbitaban alrededor de la corte, con figuras como la de Juan Ginés de Sepúlveda o de Antonio Agustín Albanell. También volveremos sobre ellos más adelante.

El grueso de los estudios sobre Mai se centraba hasta hace escasos años en el inventario de sus bienes llevado a cabo en septiembre de 1548 (dos años después de su muerte), con motivo del fallecimiento de su viuda, Eleonor Setantí. Dicho inventario es el catálogo notarial de los objetos de su legado. Basándonos en este valioso documento, vamos a intentar establecer aquí un inventario de los objetos de su hogar, además de sus numerosísimas piezas artísticas, de entre las

3. Destacando los nombres de los virreyes de Nápoles Ferran III Folch de Cardona, Joan II
d'Aragó o del embajador Jeroni Vich.

4. Duran i Sanpere (1960) y Garriga (1989). 
que destaca un grupo escultórico que ha llegado hasta nuestros días, además de muchas otras piezas de procedencia foránea. A su vez, dicho documento notarial ofrece noticia de unas cajas donde se guardaban libros sin identificar, salvo una docena de ellos.

Recientemente, sin embargo, ha aumentado espectacularmente el número de documentos acerca de Mai. Nuevos inventarios de bienes nos acercan a él desde el punto de vista material, o lo que es lo mismo, artístico, si bien también literario, ya que hemos podido identificar con bastante precisión los libros que formaban su biblioteca, lo que nos ha dado indicios de las inquietudes intelectuales del personaje. Esta nueva documentación se escribió entre 1546 y 1548, inmediatamente después de su muerte, lo que da mayor fiabilidad a la reconstrucción exacta de su patrimonio. A su vez, hemos localizado una pequeña muestra del total de su epistolario, en la que se basa también la investigación que ofrecemos ahora.

Hay todavía un conjunto de dedicatorias de obras dirigidas a Mai por parte de varios autores, de entre las que se encuentran las de los mismos Martin Ivarra y Antonio Agustín, junto a Rafael Mambla, Francesco Maria Molza y alguien que se convertirá en el segundo protagonista de nuestro texto: Antonio Sebastiano Minturno. Nos referiremos a todas estas noticias al final del presente estudio. De momento, vamos a centrarnos en los objetos o piezas artisticas de Mai, y después, en sus libros.

Lo único que se ha conservado (o que conocemos) hasta hoy del conjunto del patrimonio artístico de Mai es una parte de las piezas escultóricas que le pertenecieron. ${ }^{5}$ Su patrimonio escultórico queda consignado en su inventario de 1548 como "un conjunto de veintiún medallas de mármol, largas y redondas». ${ }^{6}$ Sin entrar a valorar aquí el hecho de que el conjunto no lo formaran ventiún medallones sino diecinueve, ${ }^{7}$ debemos interpretar todas las piezas ${ }^{8}$ como el rastro de la impronta que la cultura clásica dejó en Mai: todos son renacentistas, se adquirieron en Italia y, lo más interesante, uno de los medallones representa al propio Miguel Mai, ataviado de patricio romano (fig.1). ${ }^{9}$ Es más, Mai no solo se hizo representar a la antigua en esta medalla, siguiendo la moda de los tiempos, sino que también institucionalizó su representación pública mediante este mismo retrato. Siendo embajador imperial y para que así le conociera Clemente VII, antes de su llegada a Roma, Mai se hizo representar de esta guisa en una medalla de bronce.

5. Duran i Sanpere (1960), Garriga (1988a), Garriga (1988b), Garriga (1988c), Garriga (1988d), Garriga (1989), Garriga (1996a), Garriga (1996b), Yeguas (2007), Bellsolell (2009, inédito), Bellsolell (2009-2010) y Bellsolell (2011,inédito). 6. Arxiu Històric de la Ciutat de Barcelona (AHCB), Arxiu Notarial, I-32, 1548, folio 8verso. El texto dice exactamente: «Item vint i una medallas de marbre de diverses figures fetes de diverses maneres, ço es llargues i rodones».

7. Bellsolell (2011, inédito: 169 y ss.).

8. También se conservan dos piezas de bronce, muy probablemente de época antigua, conservadas en el Museo Marés de Barcelona. Sobre ellas, Garriga (1996c).

9. Sobre este medallón, Garriga (1988d). 


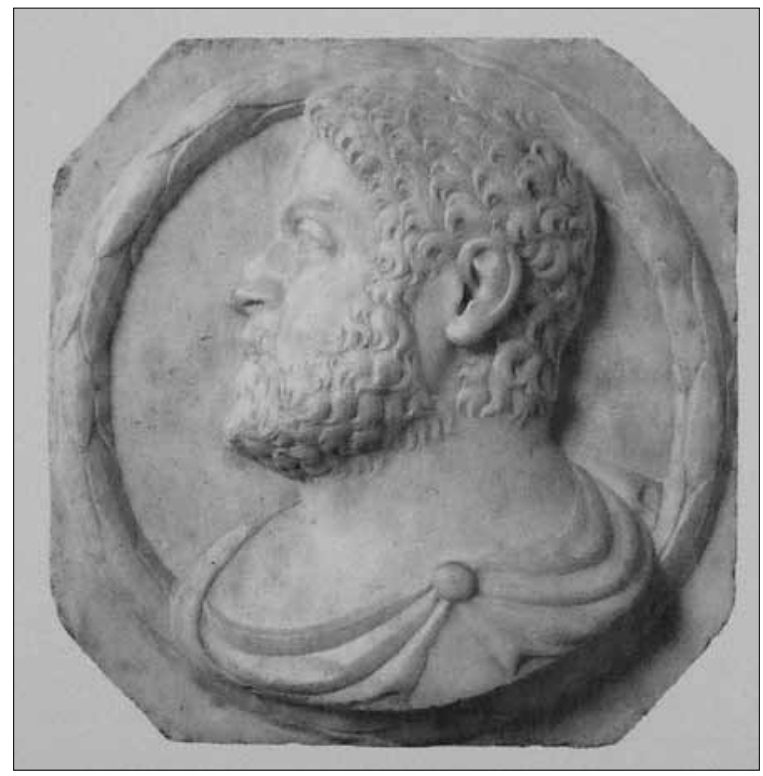

Figura 1.

Escultor anónimo. Retrato de Miguel Mai, mármol, c.1528-1533, Barcelona, Museu Nacional d'Art de Catalunya.

El retrato de dicha medalla es exactamente igual que el de la medalla de mármol, lo que nos lleva a pensar, en primer lugar, que Mai tenía establecido un modelo de representación, y en segundo lugar, que ese modelo anteponía a otras consideraciones artísticas su atracción por la cultura de la antigüedad (fig.2)..$^{10}$

Para acentuar el carácter clásico de su estética, en el reverso de la misma medalla de bronce Mai hizo grabar un episodio mitológico muy famoso, el de Heracles nińo que para defenderse de unas serpientes las estrangula con suma facilidad (fig. 3 ). ${ }^{11}$

El rastro de los medallones de mármol, junto al de otras piezas escultóricas, puede seguirse con mucho más detalle en la documentación de 1546, hasta el punto de que es posible identificar con absoluta seguridad algunos de los medallones e incluso limitar su cifra a las ya mencionadas diecinueve piezas. Cabe también destacar que los medallones de mármol iban acompañados de otra pieza (en este caso de

10. Sobre el retrato, Bellsolell (2009) y Bellsolell (2009-2010), donde se ofrece un abanico más amplio de interpretaciones iconográficas de la medalla, especialmente en lo referente a cuestiones políticas. También se ofrece la visión de otros posibles retratos localizados en distintos lugares y sobre otras superficies materiales.

11. Para la interpretación de la escena remito a la bibliografía citada en la nota anterior. 


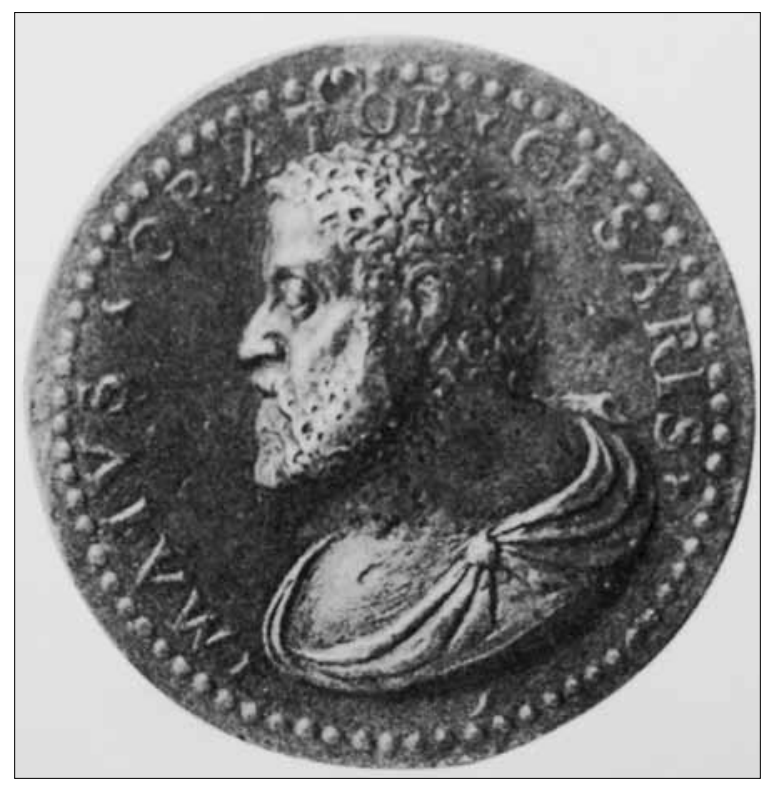

Figura 2.

Escultor anónimo, Retrato de Miguel Mai, bronce, c.1528-1533, ubicación desconocida, Colección Alois Heïss.

alabastro), que representa a una figura femenina ya en su día identificada como "La dama del armiño», por representar a una joven que sostiene en sus brazos al escurridizo animal (fig.4). La pieza se conserva en el Museo Marés de Barcelona y últimamente ha recibido cierta atención al ser identificada con la famosa Giulia Gonzaga, aunque hay matices que avalan cierta reserva. ${ }^{12}$ Porque parece que la figura representa al personaje bíblico de Priscila; es decir, es una alegoría de la virtud y el conocimiento, muy características de un buen cortesano renacentista, amante de la cultura. Por último, el capítulo escultórico queda muy bien representado en varios conjuntos de medallones (algunos de ellos sin identificación clara), de entre los que destaca un grupo de diez en los que figuran los personajes de Héctor, Virgilio, Jasón, Bruto, Aquiles, Eneas, Dido, Judit, Tisbe y Betsabé. Todos ellos, a excepción de Héctor ${ }^{13}$ se corresponden con buena parte de los protagonistas del

12. Para un análisis detallado de la pieza Garriga (1996a). Sobre la identificación con Giulia Gonzaga consultar a De Rossi (2009). Para los más escépticos sobre la identidad de la dama, Bellsolell (2011, inédito: 187 y ss). Más adelante reflexionaremos acerca de la re- lación que hubo entre Mai y la Gonzaga ya que hay evidencias de que se trataron en varias ocasiones.

13. Es posible que se produjera un error en el momento de llevar a cabo el inventario, pues quien sí aparece en la obra de Petrarca es Paris. 


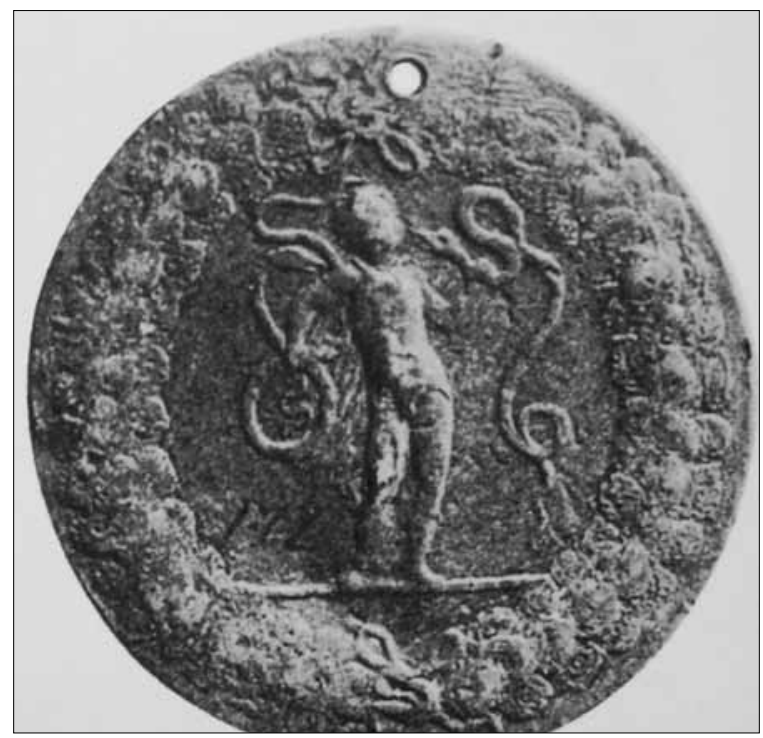

\section{Figura 3.}

«Héracles estrangulando las serpientes», reverso del medallón de bronce de Miguel Mai.

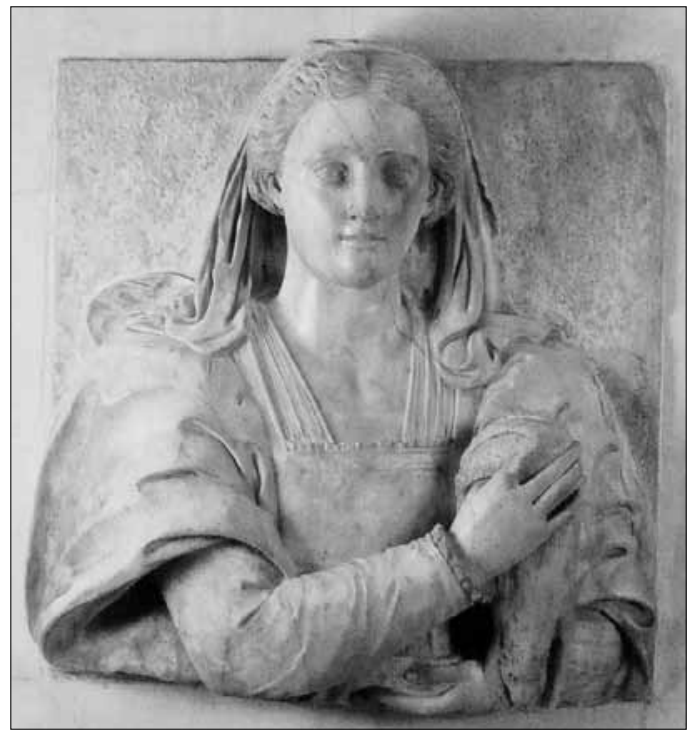

\section{Figura 4.}

Escultor anónimo, «Dama del armiño», alabastro, primer tercio del s.Xvi, Barcelona, Museu Frederic Marés. 
Triunfo de Amor de Petrarca. Este ejemplo, por si fuera poco, iba acompañado por una serie de seis tapices - la serie completa - de los seis triunfos petrarquistas que adornaban las paredes de una de las estancias de su residencia.

El conjunto decorativo de la casa de Mai se componía de otras numerosas piezas merecedoras de algún comentario. Para empezar, el capítulo pictórico. Se llegan a contabilizar más de cincuenta representaciones pictóricas en forma de cuadros o telas. Las imágenes abarcaban el asunto cristiano, especialmente el ciclo de la Pasión de Jesucristo y numerosas vidas de santos, así como también comprendían representaciones paganas, como el Laberinto de Ariadna, la historia de Diana y Acteón, alegorías de la Primavera, y por supuesto, un conjunto de telas con series de gobernantes del momento. Los mitos borgoñones tampoco podían faltar en la casa de un servidor de Carlos V; por eso encontramos la serie entera de los «Nueve caballeros de la fama» (Héctor de Troya, Alejandro Magno, Julio César, Josué, Judas Macabeo, el rey David, Carlomagno, Arturo y Godofredo de Boullion), telas pintadas que por la descripción que de ellas se nos ofrece debían de seguir el modelo instaurado por Hans Burgmair, de gran fama a lo largo del siglo Xvi.

Como ya hemos anunciado, los tapices de la serie petrarquesca ocupaban un lugar preeminente pues adornaban la entrada a la capilla de la casa. Pero de la galería que distribuía la residencia también pendían las distintas telas con las series de la Dama y el unicornio, o la historia de Griselda o los trabajos de Hércules, entre otras. Además, Mai solía acompañarse de ricas tapicerías en sus viajes, que decoraban la tienda en que descansaba.

La documentación también ofrece testimonio de la existencia de casi doscientos dibujos en papel que representan a la perfección la atracción que sobre Mai ejercía la cultura clásica. Del interés que suscitaba en Mai la arquitectura y los monumentos de la Antigüedad queda el testimonio de los dibujos de numerosas ciudades, casi siempre italianas (Roma, Milán, Génova...), con anotaciones en que se explicita que muchos de esos dibujos son de detalles de sus principales edificios. La geografía y la cartografía, junto con el interés por los nuevos territorios explorados, tampoco escapaba a su inclinación, así que aparecen muchos mapamundi a la vez que descripciones mitológicas de lo que por aquel entonces se esperaba que fuera el reino del Preste Juan. Hay a su vez distintos pliegos de papeles catalogados con nombres de algunos de los dioses de la Antigüedad, así como de las distintas virtudes cardinales y teologales. De entre todos los dibujos hay, sin embargo, un cuadernillo que llama especialmente atención, pues hace referencia a los dibujos de la villa de Poggioreale realizados por Paolo Giovio, quien durante los ańos en que Mai fue embajador en Roma estuvo al servicio de Clemente VII, y por lo tanto, tuvo sobradas ocasiones de tratar con él. ${ }^{14}$ Dicho cuaderno de dibujos reviste singular importancia porque puede relacionarse con el eje central de la relación de Miguel Mai y Antonio S. Minturno, que trataremos más adelante.

14. Maffei (1996). 


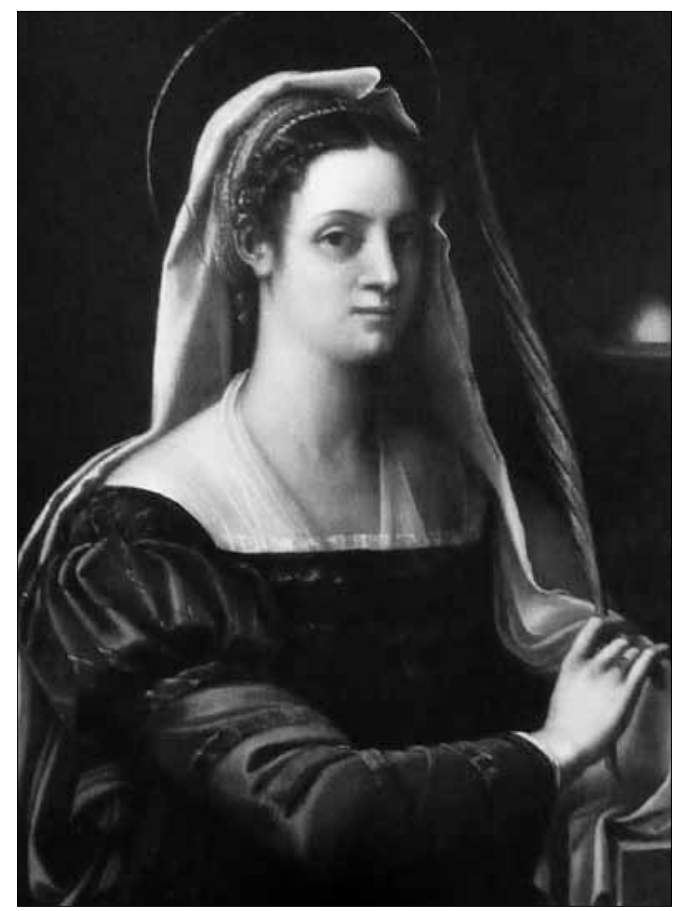

Figura 5.

Sebastiano del Piombo, Giulia Gonzaga como Santa Ágata, c.1532, Londres, National Gallery.

Otro aspecto que deja al descubierto el rastro documental son sus lecturas. Este capítulo es, sin lugar a dudas, el más importante a tener en cuenta, pues es el más clarificador, el más cuantioso y también el que más fama ha dado a Mai a lo largo de los años. Hasta hace muy poco solo teníamos unas breves indicaciones bibliográficas que citaban documentación sobre los libros de Miguel Mai, cuyo conjunto se decía que conformaba una de las bibliotecas más impresionantes del momento. Incluso se llegaba a cuantificar su número en cerca de dos mil doscientos volúmenes. ${ }^{15} \mathrm{El}$ problema es que la documentación en la que se

15. Guilleumas (1965-1967) nos indicaba la existencia de un documento donde se hablaba de los libros sin indicar su localización exacta. Duran i Sanpere (1960) ofrece breves noticias de los libros que aparecen en el inventario de 1548, donde aparecen tan solo una docena de libros. Y Rubió i Balaguer (1973) explica que examinando el mismo documento del que nos habla Guilleumas ha podido localizar ciertas rarezas bibliófilas, incluso nos da la cifra aproximada de mil ochocientas obras impresas y cuatrocientas de manuscritas, aunque tampoco indica nada concreto acerca del documento. 
centraban dichas afirmaciones se perdió ${ }^{16}$ y solo en fechas recientes se ha vuelto a localizar. En el mismo inventario de 1546 es donde se encuentra una extensa relación de las lecturas que ocuparon a Mai. ${ }^{17}$ Nuestro recuento nos acerca a la cifra de casi dos mil libros de los que entre un ochenta y noventa por ciento pueden identificarse. La combinación de materias demuestra que su propietario era alguien de gran categoría intelectual. Hay libros de jurisprudencia (como era lógico en un jurista), filosofía, teología, tratados de política, manuales de gramática, crónicas de historia de todo el mundo conocido y de todas las épocas, libros científicos (especialmente astronomía, matemáticas y medicina), tratados de arquitectura y arte, y por supuesto, obras literarias de todos los tiempos y de todos los géneros. Los formatos de los libros varían bastante pero predomina el libro impreso (muchos de ellos de talleres extranjeros) aunque también hay manuscritos. Predomina la bibliografía en latín, pero también abundan los libros en catalán, castellano, francés, alemán, italiano, griego y hebreo. Hay algunas ediciones bilingües. Esta universalidad de sus lecturas se debe al continuo movimiento de la corte imperial por toda Europa, lo que explica por qué otros cortesanos también pudieron acumular grandes bibliotecas en la misma época. ${ }^{18}$ Lo que nos interesa aquí es constatar que la fascinación por el mundo clásico no era una simple moda sino todo un estilo de vida. Entre los libros podemos localizar varias ediciones de casi cualquier autor clásico, tanto griegos como latinos. Predominan las obras de Aristóteles, Platón, Plutarco, Homero, Cicerón, Virgilio, Plinio el Viejo, Plinio el Joven, Quintiliano, Horacio, Tucídides, así como sus comentaristas de época medieval y moderna. La fascinación por la Roma Antigua se traduce en varios libros de vistas y dibujos de los monumentos que por entonces eran visibles, dados a conocer gracias a la imprenta. Andrea Fulvio es el principal autor en esta materia pero también aparecen descripciones de libros anónimos (o que no podemos identificar), compuestos por lo que el notario llama como "libros de vistas». La ciencia de la numismática, tan determinante en la época para el desarrollo de la imagen del retrato, también se recoge en volúmenes de su biblioteca particular, lo que explica en parte por qué Mai se hizo retratar de la manera que hemos mencionado.

Dejando de lado este breve resumen de los objetos que poblaban su residencia, nos adentraremos ahora en dos muestras documentales más que hacen alusión a otros aspectos de su pasión por el mundo clásico. Se trata, por un

16. El estudio de la biblioteca de Mai lo estaba realizando el profesor Josep Ma Moretó pero al morir este se perdió el rastro a la documentación. Vid. Madurell Marimón-Rubió i Balaguer (1955: 100*).

17. Examinando el documento percibimos que debe de existir algún otro inventario más preciso sobre los mismos libros, ya que el recuento de libros no es el mismo que indicaron los autores antes citados, además de algunas indicaciones que el notario hace anotar y que se refieren a otros inventarios no localizados.

18. Gonzalo Sánchez-Molero (2005), Toscano (1992) y Álvarez-Mateos (1996), Morte (1996) y Cátedra (2002). 
lado, de parte de su epistolario y, por el otro, de algunas dedictorias de obras a él dirigidas.

De su correspondencia personal apenas conservamos nada pero sí se conoce alguna carta comendaticia en la que Mai se ofrecía como mediador, junto a otras en las que se habla sobre él. De entre las cartas dirigidas a su persona destacan las de Pietro Bembo y Juan Ginés de Sepúlveda. Del primero se conoce tan solo una carta en la que si bien solo se tratan cuestiones diplomáticas y políticas, se da a entender, por otro lado, que la relación venía de lejos. Es fácil deducir que Mai y Bembo se debieron conocer cuando el primero fue embajador en Roma y hubo de coincidir con el segundo en varias ocasiones, especialmente en los actos de la coronación imperial de Bolonia. Además, hay varias obras de Bembo entre los libros de la biblioteca de Mai. ${ }^{19}$ Por lo que respecta a Ginés de Sepúlveda, también se conserva una sola carta, de octubre de 1537, en la que el distinguido humanista agradece el trato que Mai le dispensó durante su estancia en su casa barcelonesa. Ginés de Sepúlveda también le escribe para interceder en favor de un jurista zaragozano que quiere hacer carrera pública bajo la protección del mismo Mai. ${ }^{20}$ El vínculo entre ellos debió de ser cercano al familiar pues se detecta en las palabras de Ginés cierta camaradería que solo se da en una relación muy estrecha. Esta relación es también fácil de rastrear. Ambos coincidieron durante años en el séquito de la corte; especialmente intensos debieron de ser los años en que ambos compartieron en Roma ocios, charlas y lecturas. Durante los años de su embajada se da la polémica entre Erasmo y Ginés, con floración de textos que debatían las ideas de ambos; el más destacado de todos es de la pluma del príncipe Alberto Pío. Al cordobés le iría muy bien en ese momento tener a su lado un erasmista convencido como Mai que, además, conocía en persona al mismo Erasmo, ya que juntos trataron asuntos de la corte durante 1521, en el viaje del Emperador por tierras alemanas. Como es lógico, también los textos derivados de esa polémica se encuentran entre las lecturas del barcelonés.

De las cartas en las que otros personajes escriben en nombre de Mai surge uno de los capítulos más interesantes de su biografía. Se conservan y se conocen una docena de cartas escritas en su nombre por alguno de sus dos secretarios, Girolamo de' Medici y Gian Battista Albrisio, y dirigidas al duque de Mantua Federico II Gonzaga. ${ }^{21}$ Tales cartas abren un capítulo de la historia del arte y la cultura en general, como pocos se conocen sobre este período. Las cartas se escribieron entre mayo y octubre de 1536, aprovechando que la corte se encontraba en Génova, de vuelta de la campaña en el norte de África. En los escritos se hace saber al duque Gonzaga que Miguel Mai está interesado en decorar una sala

19. Travi (1987-1993).

20. Losada (1979).

21. Bodart (1998). La autora publica la relación de cartas con los fragmentos centrales que hablan del tema. Además también nos da todas las referencias archivísticas, lo que nos permitirá en el futuro hacer una visura de la correspondencia entera. 
de su residencia con un ciclo pictórico de la vida de Virgilio. Dicho ciclo pictórico debe ser a semejanza de otro conjunto pictórico que Mai vio en la residencia del duque en la villa de Pietole, cerca de Mantua. También se le hace saber al duque que Mai estaría muy interesado en que Giulio Romano, el pintor estrella de aquel momento (o alguien de su taller), se hiciera cargo de la confección de unos dibujos que sirvieran para que una vez en Barcelona, algún pintor pudiera trasladarlos al formato requerido para su función decorativa. El encargo de tan interesante ciclo se termina con la realización de un cuaderno de nueve dibujos. No extraña que quien encargara la obra fuera alguien como Mai, al servicio de una corte en que las modas virgilianas habían afianzado su tradición desde hacía tiempo. ${ }^{22}$ Pero, curiosamente, el encargo hace referencia a "una vida de Virgilio" y no a la obra más importante del poeta de Mantua, la Eneida, que hubiera encajado a la perfección en la dimensión imperial del comitente de la obra. En cualquier caso, entre la documentación encontrada no se observa nunca una referencia explícita a lo que podrían ser los dibujos solicitados. Si acaso puede llamarnos la atención un cuaderno (de los muchos que encontramos) que está formado por nueve «papeles pintados», sin especificar su tema.

En el tercer grupo de epístolas que hemos distinguido, el de las cartas que hablan sobre Mai, de nuevo hay alusiones a éste como personaje convencido de la primacía de la cultura clásica. Entre noviembre de 1544 y noviembre de 1546 (cuatro meses después de su muerte), Hernán Pérez de Guzmán el «Pinciano», Jerónimo Zurita y Cristóbal de Horozco se cartean sobre diversos asuntos. Entre ellos está el anuncio de que el Pinciano ha publicado sus comentarios sobre Plinio; es decir, las Observationes in Plinium, un libro localizable en los inventarios. Núńez de Guzmán asegura que ha hecho mandar varios ejemplares a distintas personalidades de la corte, entre ellas a Mai. Sorprende que el Vicecanciller también aparezca por ser el propietario de unos libros de refranes, de gran interés entre los interlocutores. Pero lo más curioso del caso es que, recién fallecido Mai, Zurita escribe a Juan Páez de Castro, cronista del Emperador, preguntando por la librería que Mai siempre llevaba consigo en sus viajes. Lamentablemente, no se menciona ningún título, salvo una breve referencia a los libros de jurisprudencia que se guardaban en varios cofres. ${ }^{23}$

Una última carta nos parece significativa. Es la que Vicenç Navarra, canónigo de la Catedral de Barcelona, dirigió a Alfonso de Valdés, secretario de Carlos $\mathrm{V}$ para los asuntos tratados en latín. En ella el canónigo explica un encontronazo entre Mai, el mismo Navarra y un jurista barcelonés llamado Rafael Joan, contra el prior de Sant Jerónimo de la Murtra (en los alrededores de Barcelona), sobre la conveniencia de la lectura del Nuevo Testamento, editado recientemente por Erasmo. Frente al ataque de cólera del prior por considerar las lecturas de

22. Vilà (2007) y Belda (1985).

23. Codońer (2001). 
Erasmo heréticas, Mai alabó su discurso acerca de la crítica textual de las fuentes originales y la conveniencia de la lectura de los clásicos, así como de las ediciones modernas, poniendo como ejemplo a Poliziano. ${ }^{24}$ La carta se escribió cuando Mai ya se encontraba en Roma, con motivo de la alarma que causaba que el erasmismo se hubiera disipado casi por completo de Barcelona tras la marcha de Mai a la ciudad eterna, anulándose así un centro cultural muy activo.

Por útimo, las numerosas dedicatorias a él dirigidas en obras de autores como Martin Ivarra, Antonio Agustín, Rafael Mambla, Jerónimo Amphioni, Francesco Maria Molza y Antonio Minturno, nos perfilan todavía más su profunda implicación en el mundo del arte y las letras. Ivarra le dedicó dos obras, en la primera de ellas, Aelii Antonii Nebrissensis Relectio nona de accentu latino (1514), escribió el mayor elogio conocido acerca de la biblioteca de Mai: «Bibliothecam tuam plurimi qui visunt, universam Italiam se credant peregrase». ${ }^{25}$ Unos años más tarde, en 1522, le dedicó la segunda, el Vocabulario de Nebrija. ${ }^{26}$ Mencionábamos un poco más arriba los medallones y la colección de numismática; Antonio Agustín le dedicó a Miguel Mai tres de los cuatro volúmenes de un manual de jurisprudencia titulado Emendationes et Opinionum (1543). Pero Agustín se dio a conocer por sus catálogos de numismática, y sus conocimientos sobre la Antigüedad, que solo pudo adquirir bajo la protección de nuestro político, pues el padre de Agustín, colaborador de Mai en la corte, murió cuando el futuro obispo de Tarragona era todavía un niño. ${ }^{27}$ El caso de un escritor autóctono como Rafael Mambla parece distinto a los dos anteriores. Si con Ivarra y Agustín el patrocinio literario se debe a razones políticas o de dependencia económica, Mambla escribe una dedicatoria en agradecimiento al apoyo de Mai en la introducción de los estudios de Dialéctica en la Universidad de Barcelona. En 1540, Mambla le dedica su De dialectica sive rationali philosophiae, refiriéndose a Mai como a un renovador de la educación universitaria. ${ }^{28} \mathrm{El}$ abad de Benifassá, Jerónimo Sans, le dedicó, por su parte, dos obras de carácter histórico, el Aragonnum clara insignia regnum (publicada en Valencia en 1541) y la Vita Johannis II. Las dos obras se han perdido pero en el inventario de los libros aparecen títulos que pueden corresponderse con ellas. ${ }^{29}$ No nos es dado identificar a Jerónimo Amphionii, pero se conserva un ejemplar de su In portentum novum en la biblioteca del Real Seminario de San Carlos de Zaragoza donde se dispensa a Mai el trato de "principi eminensum». ${ }^{30} \mathrm{Y}$ reservamos para el final los dos autores que nos abrirán paso al núcleo de este estudio: Francesco Maria

24. Caballero (1875), Bataillon (1983), Duran (1986) y Duran-Solervicens (1996).

25. Traducción: «Muchos de los que ven tu biblioteca creen estar visitando toda Italia». García Martínez (1986) y Duran (2004).

26. Batllori (1995).
27. Flores Sellés (1980), Moles (1990) y Duran (1993). Agustín y Mai también coincidieron en su gusto por lo virgiliano. Sobre ello, Carbonell Manils (1994).

28. Duran-Solervicens (1996).

29. Querol (2006).

30. Kristeller (1989). 
Molza y Antonio Sebastiano Minturno. El primero de ellos parece mantener una estrecha relación con Mai gracias a los años que pasaron juntos en Roma y sobre todo a la amistad que unía a ambos con uno de los principales mecenas del momento, el cardenal Alessandro Farnese, futuro Paulo III.

Molza, poeta célebre de la ciudad de Modena, dedicó a Mai el segundo de los cuatro volúmenes de sus Elegías, junto con las dedicatorias a León X (primer volumen), Alessandro Farnese (tercer volumen) y Carlos V (cuarto volumen). También dedicó a Mai un conjunto de poemas de los que no tenemos noticias. ${ }^{31}$ Más adelante veremos a Molza en relación con los principales círculos culturales de la corte, que tendrán en Miguel Mai y otros distinguidos personajes una conexión muy especial en la ciudad de Nápoles.

Adelantaremos aquí un detalle revelador acerca de lo que fue la relación de Mai con Antonio S. Minturno: el futuro obispo de Crotona dedicó a Mai una edición del Convitto de sette savi de Plutarco, además de numerosos grupos de sonetos. Estos, junto con otras obras del mismo Minturno, se encuentran en su biblioteca. De todas formas, entre Mai y Minturno se desarrolló una relación literaria que va más allá de la mera dedicatoria de circunstancias, como veremos a continuación. ${ }^{32}$

\section{La relación epistolar entre Miguel Mai y Antonio Sebastiano Minturno}

Antonio Sebastiano Minturno, originario de Traetto, fue más conocido en su tiempo por haber sido el obispo de Urgento y Crotone y por ser uno de los personajes más activos durante el Concilio de Trento, que por ser uno de los principales estandartes de la cultura humanista-renacentista. En sus inicios, Minturno se encontraba al servicio de la casa de los Pignatello, familia de potentados sicilianos, vinculados a la facción proimperial. Desde esta plataforma social no fue difícil el ascenso de nuestro obispo hasta las cotas más altas. ${ }^{33}$

Lo que no está tan clara es su vinculación con Miguel Mai. Sabemos que la familia Mai tuvo intereses en Sicilia desde finales del siglo xv, cuando el padre de Miguel, Joan Mai, anduvo al servicio de los virreyes de la isla. Incluso años más tarde, el hermano de Miguel, también llamado Joan Mai, fue nombrado por Fernando el Católico abad de la iglesia de San Salvador de Mesina. ${ }^{34}$ Tampoco hemos de descartar la posibilidad que Miguel hubiera estado en Sicilia por motivos de responsabilidad política en función de su cargo como regente del reino de Cerdeña entre 1512 y 1520 . Viendo este panorama parece plausible que Minturno hubiera oído hablar de Mai cuando entró al servicio de la

31. Kristeller (1977) y Molza (1999).

32. Kristeller (1989).

33. Sobre su biografía, Rizzi (1998) y más re- cientemente Minturno (2009).

34. Sans i Travé (2004) y De la Torre (19491966). 
familia Pignatello, y así, podríamos retrasar el conocimiento mutuo (o al menos el de Minturno respecto Mai), a antes de que Miguel se hiciera célebre por su nombramiento como embajador en Roma. Y es que la relación epistolar que se desarrolla entre ellos empieza precisamente con motivo de la embajada que acabamos de mencionar.

Conservamos hasta once misivas de dicha relación epistolar: las escribe Minturno entre 1534 y 1542, y lamentablemente no contamos con ninguna de las respuestas que Mai envió. Las editó Minturno en su compilación epistolar de 1549 , cuando ya hacía años que Mai había fallecido, lo que indica que su amistad fue significativa para el obispo-humanista. ${ }^{35}$

Todas las cartas presentan una misma estructura: empiezan por una adulación del remitente al destinatario, luego se presentan los motivos por los que se escribe y finalmente hay una despedida deseando lo mejor a Miguel Mai, así como una oferta de todos los servicios posibles por parte de Minturno. Cada una de las once cartas, además, aportan noticias frescas de la corte imperial pues Minturno hace mención en todo momento a distintos personajes que parecen formar parte del círculo de Mai, así como de otros que hacen las veces de intermediarios entre ambos. Es el caso por ejemplo de nombres tan significativos como Luis de Ávila o Nicolás de Granvela. No debe sorprendernos que otros potentados de la corte aparezcan de por medio pues en su misma relación de cartas publicadas también se mencionan otras dirigidas a nombres como Francisco de los Cobos, el mismo Granvela y otros ministros de Carlos V.

Es el interés por la corte lo que lleva a Minturno a escribir a Mai. En su primera carta (carta $\mathrm{n}^{\circ} 1$ ) de diciembre de 1534, ya muestra sus intenciones de incorporarse al séquito de Mai y así estar en disposición de promocionar algunas de sus composiciones. No solo le escribe para ofrecerse: el primer texto es una adulación del personaje de Mai como embajador imperial en el pasado. Esta es la causa que esgrime para no haberse puesto en contacto con él, pues no quería dar la impresión de intentar sacar provecho de la situación extraordinariamente privilegiada de Mai. Minturno nos ofrece una información interesante para entender la relación; nos comenta que sabe de las buenas maneras de Mai gracias a Andrea Ardoino, Conservador del Real Patrimonio de Carlos V. De hecho, Minturno escribe su primera carta para hacerle llegar a Mai «la canzone da confortare i Principi Christiani alla impresa contro à Turchi», una obra que podríamos identificar con el De adventu Caroli, obra que Minturno escribió para dedicársela a Nicolás de Granvela y que figura en las bibliotecas de Mai y del mismo Granvela. ${ }^{36}$ Además, le comunica que su "canzone» es una obra escrita en toscano y en rimas italianas. Junto a este texto, también añade ciertas composiciones latinas que ha mandado a otros cortesanos.

35. Minturno (1549). Al final del presente texto añadimos un apéndice de las once cartas, editadas en el mismo orden que les dio Minturno.

36. Toscano (1992). 
La segunda misiva (carta $\mathrm{n}^{\circ}$ ) no dispone de fecha (igual que la tercera) y por ello debemos suponer que Minturno las publicó en su orden correcto. Dejando de lado las ocurrencias retóricas que Minturno emplea para ensalzar con hipérbole la virtud de Mai, en la carta Minturno expresa su voluntad de incorporarse a la corte bajo la protección de Mai. Esta segunda carta es muy significativa, puesto que Mintuno escribió con las mismas intenciones a varios hombres de estado del momento aunque con ninguno de ellos se estableció una relación epistolar tan larga como la que se dio con Mai, lo que no se podría haber dado si el jurista catalán no hubiera sentido especial interés por Minturno.

En esta segunda epístola asoman expresiones como es la conocida «mandava Nottole ad Athena», paremia de origen griego, usada por Cicerón, divulgada en el siglo Xvi gracias al Ariosto y sobre todo Erasmo de Rotterdam, ${ }^{37}$ autores preferidos de Mai. En la misma carta, Minturno anuncia su traducción del Convitto de sette savi de Plutarco, obra que finalmente le dedica a Mai. Junto al Plutarco, le envía una compilación de poemas dedicados a la paz entre el Emperador y el rey de Francia.

En la tercera carta (Carta no3) se trata a Mai de mecenas de la cultura, algo exagerado pues nunca pasó de ser un comitente que satisfacía así sus aficiones culturales, y en ningún caso (que sepamos) tuvo a su servicio a artistas que trabajaran en exclusiva para él. Minturno aporta informaciones nuevas sobre Mai que ya sospechábamos: Mai es un gran defensor del estudio de la elocuencia y del conocimiento, empeños muy acordes con el elogio que le dedicaría Mambla poco más tarde. Figura también aquí la confirmación de que Minturno le dedicará la traducción de Plutarco que ya estaba elaborando en la carta anterior. Es una lástima que no dispongamos de las respuestas de Mai para conocer cuál era su perspectiva acerca de las obras que se le enviaban y se le dedicaban.

Minturno escribió la cuarta misiva (carta no4) en marzo de 1540, mientras la siguiente carta (carta $n^{\circ} 5$ ) es de junio de 1539 . Resulta estraña tal alteración y no deja de ser curioso que entre las primeras cartas (que son de la misma época), y estas dos, hayan pasado cinco años. Varias misivas deben de haberse perdido por el camino. También debemos tener en cuenta que en 1536 Mai y Minturno coincidieron durante unos meses en la estancia de la corte en Italia, por lo que el trato epistolar dejó de ser necesario. Se abren aquí unos años de silencio. Por lo que respecta al contenido de los documentos, llama la atención la aparición del duque Pignatello, o del virrey de Sicilia (sin especificar cuál, aunque probablemente se refiera al duque de Monteleone), Carlos V y el ministro Granvela. Parece ser que en este momento Minturno pasa por un mal momento ya que no goza del favor de la corte a causa de desavenencias entre el Emperador y los Pignatelli, lo que dificulta su dedicación a la poesía. Así se disculpa Minturno por sus retrasos epistolares.

37. Menor (2009). 
Minturno le hace saber a Mai que le enviará un ejemplar del Panegyrico, un texto en el que Giovanni Gesualdo escribe acerca de la figura del poeta y la poesía inspirándose en Petrarca. Parece que Minturno intentaba recordar su oficio de poeta apoyándose en las reflexiones de Gesualdo, ya que en aquellos tiempos se encontraba más ocupado en cuestiones teológicas que poéticas, a la vez que sus antiguos protectores de Sicilia carecían de la consideración de la corte, lo que conllevaba cierto aislamiento con respecto a quienes sí que gozaban de protección imperial. ${ }^{38}$

La sexta epístola (carta $\mathrm{n}^{\circ} 6$ ) es de diciembre de 1539, es decir, anterior a la cuarta carta y posterior a la quinta. Aparte de recordar el prestigio del duque Pignatello, Minturno no pasa de hacer una referencia a la musas y las virtudes tantas veces atribuidas a Mai, a las que Minturno apela ahora para conseguir su favor. En la séptima (carta no7), con fecha de 1540, Minturno le informa de que continúa formándose en la doctrina griega y que espera poder ser honrado con la gracia del Emperador «tal como ha hecho aceptando otros estudiosos en su séquito", y que también espera una restauración de la posición de los Pignatelli, algo que le beneficiaría mucho. Minturno también pregunta por Luis de Ávila y Zúńiga, conocido historiador y cronista, compañero de Mai en la misma corte en varios círculos y facciones. Aparecen a su vez otros personajes que no sabemos identificar con precisión, como el señor Morano.

Las últimas cartas (entre 1541 y 1542, cartas no8, 9, 10 y 11) son las más interesantes en lo que a cuestiones literarias se refiere, ya que en ellas Minturno entabla una discusión con Mai sobre el papel de las musas y las divinidades en la poesía (lo que nos hace lamentar todavía más la pérdida de las cartas de respuesta de Mai e incluso algunas del mismo Minturno), especialmente en lo que concierne a la musa Giove y al dios Apolo. Tampoco cabe olvidar la relevancia de las comparaciones que se establecen entre la situación de Minturno con respecto a Mai y el tribunal del Areópago y la diosa Atenea; es decir, Mai es el juez que deberá decidir si Minturno es un auténtico poeta o, por el contrario, caerá en el olvido de la historia. El de Traetto está preparando el discurso que años más tarde publicará en su De Poeta; lo curioso es que ya menciona esta obra por su título, como si fuera una realidad: desde la Antigüedad se teorizaba sobre la poesía latina y griega y él hace suyas las convicciones de Horacio, Petrarca y Boccaccio en «su Poeta». Un elemento une aquí a Mai y Minturno: en el De Poeta, su autor expone su poética, explícitando las influencias virgilianas sobre los principales autores napolitanos del momento, a algunos de los cuales Mai había tenido ocasión de tratar; además de que la obra de buena parte de ellos está consignada en su biblioteca (como la Stanze del Fuscano, la Crónica de Nápoles, la Arcadia, el Dialogo de Amore, el Natura de amore, entre otras muchas otras obras del momento). El De Poeta es todo un debate académico,

38. Curiosamente, por estos años es nombrado Virrey de Sicilia, desde 1535 a 1546, Ferrante Gon-

zaga, que mantenía una muy buena relación con la corte y con Miguel Mai. Cf. Ochoa Brun (2003). 
actividad intelectual a que Mai no era en absoluto ajeno, como evidencian sus vínculos con el Estudio General de Barcelona. Por otro lado, en el mismo texto, Minturno confirma el envío a Mai de un ejemplar de la obra de Gesualdo a través de una tercera persona.

Esta correspondencia constituye un claro ejemplo de la imbricación estrecha que se establece entre política y cultura en el hispano-italiano siglo xvi. Las once cartas que hemos comentado aquí suponen solo un pequeño muestrario de lo sucedía, pues faltan muchos otros documentos.

\section{Cruce de caminos en la italianización de la corte}

No parece que Minturno fuera el único personaje con quien Miguel Mai solía discutir sobre literatura; es más que probable que su relación afectara a más de un escritor del mismo período. Entre agosto y septiembre de 1535, de vuelta de la campaña de Túnez, la corte se estableció unos meses en la ciudad de Nápoles y durante unos días se hospedó en la famosa villa renacentista de Poggioreale. La villa de Poggioreale se había erigido durante el reinado de Alfonso II de Aragón, bajo la dirección del arquitecto Giuliano da Maiano; siempre se la llamó Poggioreale o la Duchesca. ${ }^{39}$ El edificio, del que no se conserva absolutamente nada, parece que recibió un trato decorativo muy espectacular (con ciclos pictóricos varios) pero lo que realmente llamaba la atención a los visitantes era la arquitectura externa al edificio, en forma de jardines, fuentes, pabellones para gozar del paisaje, animales exóticos, zonas de bosque en las que desarrollar actividades cinegéticas. Lamentablemente, ya en época de Carlos $\mathrm{V}$ la villa estaba en mal estado aunque su prestigio seguía en lo más alto gracias a las descripciones de algunos autores, de entre los que destacó Paolo Giovio. ${ }^{40}$

Giovio realizó una serie de descripciones, reunidas en un cuaderno, que circularon en una pequeña edición a partir de 1536. En ellas, el autor combinaba el texto con algunas reconstrucciones en forma de dibujos. No nos debe sorprender que Miguel Mai dispusiese de uno de estos cuadernos pues en su inventario de bienes de 1546 aparece un "cuaderno de doce folios de Poggioreale» que pueden muy bien ser las páginas que escribió Giovio. Teniendo en cuenta, además, que Mai y Giovio coincidieron varias veces en Roma a causa de las funciones diplomáticas de ambos, parece lógico que el catalán se interesase por uno de los monumentos renacentistas más importantes del momento en el reino de Nápoles, pués disponía de innumerables muestras de arte y literatura clásicas que avalaban su carrera en esa dirección.

La relación artística con Nápoles no termina aquí. Con motivo de la visita imperial, el virrey Pedro de Toledo organizó unos fastos dignos de Carlos V

39. Maffei (1996).

40. ibid: 164 . 
para así afianzarse en su poder. Los organizadores de tales eventos no fueron otros que Marcantonio Epicuro, de la Academia Pontaniana, y el secretario Martirano, quien en las cartas de Minturno (carta no8) es el encargado de hacer llegar a Mai un ejemplar del Panegyrico de Gesualdo. ${ }^{41}$ Para los festejos se decoraron las calles de Nápoles con las mejores galas: arcos de triunfo, estucturas de cartón-piedra, tejidos lujosos, pinturas, telas y tapices, esculturas... todo ello aderezado con los repertorios iconográficos de Girolamo Santacroce y Giovanni Merliano da Nola. Los artistas eran escultores conocidos de la élite cortesana. El primero, Santacroce, trabajó con el principal escultor castellano del momento, Bartolomé Ordónez, quien hizo los trabajos para la estructura del trascoro de la catedral de Barcelona. El segundo, Merliano da Nola, construyó nada menos que el sepulcro-mausoleo del virrey de Nápoles, Ramón de Cardona, que había tenido estrecho trato con Miguel Mai. Los dos escultores eran absolutamente clasicistas, hasta el punto de que los lemas y las divisas que hicieron poner en todas las decoraciones de Nápoles contenían constantes referencias a la literatura virgiliana e incluso se atrevieron a dar la bienvenida a la corte con frases enteras de las obras de Sannazaro. ${ }^{42}$

La estancia de la corte conllevó que la élite política y cultural de todos los territorios italianos se desplazara hasta allí. Estar en el lugar y en el momento adecuado podía significar un ascenso, un cargo o el patrocinio de un cuadro o un libro. Pero además de los intereses propios de cuantos aparecían, también había reuniones en las que se discutía todo tipo de asuntos. Desde hacía años, Nápoles se había ganado un prestigio como centro cultural gracias a sus estudios sobre los clásicos y especialmente por la actividad que se desarrollaba en la Academia Pontaniana. Por este contexto algunos autores castellanos y catalanes se fueron hacia Nápoles, apovechando también la familiaridad que había con aquellas tierras. Aprovechando también la reunión napolitana numerosas pesonalidades que ya vivían en Italia se acercaron a participar de la solemnidad del momento.

Entre los principales nombres de literatos que debemos mencionar aquí hay dos que llaman la atención especialmente porque compartían con Mai algo más que el gusto por el mundo clásico. Se trata de los barceloneses Benet Garret y Juan Boscán. ${ }^{43}$ Cierto es que Garret, o como entonces se le llamaba, el Cariteo, es anterior a todo este capítulo, pero aún así es un personaje a tener en cuenta, porque se movió en los mismos círculos políticos que Joan Mai, padre de nuestro protagonista, ${ }^{44}$ pues estuvo al servicio de la Cancillería Real de Nápoles como agente Fernando el Católico. ${ }^{45}$ Sus obras se encuentran, además, consignadas en

41. Sin duda debe de tratarse de Bernardino Martirano, cuya villa sirvió de residencia a la misma corte imperial en su estancia napolitana. 42. Hernando Sánchez (1987) y Toscano (2001).

43. Para una aproximación a la literatura que se creó sobre la villa, Addesso (2005), especialmente por la bibliografía antigua que cita.

44. No hay constancia de que tuviera ninguna relación directa con el mismo Miguel Mai.

45. Segarra (1998), Segarra (2007), Fenzi

(2002) y sobretodo Parisi (2000). 
el inventario de los libros de Mai. Pero por encima de todo hay que recordar la influencia literaria que ejerció en poetas que sí compartieron su estancia con Miquel Mai en Nápoles durante los meses de 1535. Garcilaso de la Vega, sin ir más lejos. ${ }^{46}$

Con quien sí tuvo más relación Mai fue con Boscán, tanto por afinidades literarias y artísticas (la casa de éste en Barcelona parece ser que también contaba con una decoración muy cuidada), como por su relación directa con el mundo de la corte. Boscán estuvo al servicio del Emperador en varias ocasiones y a veces viajaba junto a la corte, pues estaba a su vez al servicio del Almirante de Castilla, Fadrique Enríquez. Pero no se encontraba en Nápoles con la corte pues no participó en la guerra norteafricana; estaba en ese momento en Barcelona, al cuidado de asuntos personales. De hecho, si seguimos las cronologías de Mai y Boscán veremos que tienen varios capítulos en común e incluso podríamos entresacar algún vínculo familiar entre ellos. ${ }^{47}$ En el caso de Boscán debemos tener en cuenta otra relación. El poeta fue el encargado de traducir El Cortesano de Castiglione ${ }^{48}$ diplomático que también tuvo durante años trato con Mai. ${ }^{49}$ Como es bien sabido, Boscán compartía, además, una entrañable amistad con Garcilaso de la Vega. ${ }^{50}$

La corte se encontraba en la villa de Poggioreale (y es posible que Garcilaso también se encontrara allí), cuando se produce el silencio epistolar entre Mai y Minturno, lo que nos hace sospechar la posibilidad de un contacto mutuo entre los tres, en forma de discusiones y tertulias cortesanas, algo que intentaremos aclarar a continuación. Las tertulias literarias fueron una realidad en la corte, lo que nos lleva a preguntarnos cuál fue el círculo de discusión de Mai.

¿Quienes fueron los protagonistas de tales tertulias? No podemos saber con total exactitud quienes eran pero hay suficientes indicios para aventurar varios nombres de personajes muy destacados. ${ }^{51}$ Como ya hemos mencionado, en las cartas de Minturno a Mai hay un vacío temporal de unos años en que se intercala el intérvalo temporal de los meses en que la corte se encuentra en Nápoles. Dicho vacío suponemos que se debe a que los dos protagonistas se hallaban en el mismo lugar, algo que parece confirmar todo su epistolario, pues con el resto de sus interlocutores Mai deja de escribirse por las mismas fechas. ${ }^{52}$ Lo que con-

46. Morros (2000)

47. Morros (2008a). Sobre la cuestión familiar deberíamos desplegar los árboles genealógicos de las dos familias para establecer dicha relación y esto es algo no aquí no nos compete. 48. En una cronología muy curiosa pues coincide con el paso fugaz de Mai por Barcelona. 49. Castiglione (2003). No existe prueba documental de que se hubieran conocido pero por sus posiciones cerca del emperador parece lógico pensar que coincidieron en algunos momentos. 50. Morros (2008 a). Dejamos apuntado tam- bién aquí que la familia de Mai era conocida por Garcilaso de la Vega, o al menos, por el padre del poeta, pues a finales del siglo xv y principios del XVI, siendo embajador en Roma, Garcilaso de la Vega padre se encargó de conseguir que Joan Mai, hermano de Miguel, fuera distinguido por Alejandro VI Borgia con el cargo eclesiástico de abad en San Salvador de Mesina. La documentación se encuentra en De la Torre (1949-1966).

51. Toscano (1994).

52. Minturno (1549) 
firma que todos formaban parte del mismo círculo de amistades. Otro caso es el de Nicolás de Granvelle, gran amigo de Mai y lector compulsivo de la literatura italiana, ${ }^{53}$ además de ser uno de los interlocutores epistolares del mismo Minturno, quien también le dedica alguna de sus obras como el De adventu Caroli. ${ }^{54}$

Pero hay alguien que sobresale muy por encima de los demás como nexo entre la tradición italiana ya establecida desde finales del siglo $\mathrm{XV}$ y los nuevos hábitos cortesanos. Se trata de Garcilaso de la Vega, un personaje cuya trayectoria ilumina las causas por las que que Miguel Mai acabará contactando con Minturno, mientras era conocido (o amigo) y coincidía con poetas como Boscán, Valdés, Molza, Bembo o Tasso. Hay que sospechar que si Mai y Minturno pudieron dialogar sobre poética, un punto en común entre ellos debería de ser Garcilaso de la Vega, seguidor de la poesía y las ideas que Minturno describiría más adelante en el De Poeta, y que el mismo Garcilaso pudo conocer en alguna conversación con el mismo Minturno en Nápoles, de la misma manera que Mai con Minturno, a través de las cartas que se enviaron. Debemos tener en cuenta, a su vez, ciertos posibles paralelismos entre la teoría de Minturno y las églogas de Garcillaso, contingencia que se explicaría porque cabe dentro de lo posible por ambos poetas coincidieran, además de puntualmente en Nápoles, con más tranquilidad en Sicilia. ${ }^{55}$

Por otro lado, Garcilaso trató con otros autores que se carteaban con Mai, como Pietro Bembo, con quien coincidieron ambos en los actos de Bolonia en 1530. Garcilaso llegó también a oídos de otro de los grandes autores italianos del momento, Francesco Maria Molza, poeta de Modena. ${ }^{56}$ Fue miembro de la Academia de la Virtud de Roma, formando parte del mismo círculo que Marcantonio Flaminio. Estuvo bajo la protección de los Medici florentinos y disfrutó del amparo del cardenal Alessandro Farnese, futuro papa Pablo III. Coincidió con Mai en Roma; se explica que Molza le dedicara su obra por el hecho de que tuvieron que encontrarse allí en muchas ocasiones con motivo de la comisión que por entonces estudiaba el caso del divorcio de Catalina de Aragón y Enrique VIII, una comisión a la que pertenecían el mismo Mai y el cardenal Farnese. ${ }^{57}$ Molza dedicó alguna de sus obras a Miguel Mai, como el segundo volumen de sus cuatro libros de Elegías. El primer libro lo dedicó al papa León X Medici; el tercero, al cardenal Farnese y el cuarto, al emperador Carlos V. ${ }^{58}$ También dedicó a Mai un conjunto de poemas a su vez dirigidos a personajes como el papa Clemente VII, Ercole d'Este o Benedeto Accolto. ${ }^{59}$

Lo interesante de la relación entre Molza y Mai es que los escritos de Garcilaso también llegaron a manos del poeta de Modena, justo en el momento en

53. Y también de la pintura pues se le conoce la posesión de diversas obras de Tiziano.

54. Las cuales encontramos en el inventario de su biblioteca en Besançon. Sobre ello Toscazo (1992).
55. Fosalba (2009)

56. López (1988).

57. Serassi (1808).

58. Kristeller (1977).

59. Ibid. 
que la corte se encontraba en Nápoles, en 1535, cuando hacía años que Mai y Molza ya se conocían, y muy probablemente fue Bernardo Tasso quien desempeñó el papel de intermediario entre Molza y Garcilaso, una de las amistades de Minturno que Mai pudo haber conocido también en esta estancia napolitana. Tasso también tenía trato personal con Molza. ${ }^{60}$

Regresando al círculo de amistades napolitanas, debemos mencionar a Juan de Valdés y al secretario Bernardino Martirano. El primero gozó de gran estima por parte del Virrey Pedro de Toledo, a cuyo servicio estaba, quien a su vez protegía a Garcilaso. Por su parte, Juan de Valdés fue a parar a Nápoles por indicación de Mai, pues estando los dos en Roma, el fantasma de la herejía se cernía sobre él, y nuestro embajador, también cuestionado por sus inclinaciones erasmistas, le recomendó que se pusiera al servicio de la corte virreinal. Valdés era uno de los protagonistas de las tertulias literarias en Roma, junto a hombres de la talla de Molza, Flaminio, el cardenal Farnese y, mujeres como Giulia Gonzaga Colonna.

Es de rigor mencionar al secretario Bernardino Martirano por ser el anfitrión de la corte durante algunos de los días previos a la entrada real en Nápoles de Carlos V. Se ha llegado a sugerir que fue el organizador de la nueva Academia Pontaniana a la muerte de Sannazaro (aunque también se ha pensado en un núcleo alrededor de Valdés), ${ }^{61}$ y no sería de extrañar pues se le conocen algunas composiciones poéticas que lo definirían como hombre preocupado por las nuevas formas literarias y por la recuperación de la literatura clásica. ${ }^{62}$

Habiendo nombrado a la bella Giulia Gonzaga como una de las posibles interlocutoras de la corte, debemos tejer unos últimos hilos más de esta red social. $Y$ es que parece increíble que algunos de los nombres femeninos que más hemos de destacar también tengan tanta relación con Antonio S. Minturno y Miguel Mai. Se tratan de la mencionada Gonzaga y de Maria de Cardona. Cierto es que en la estancia cortesana en Nápoles había muchas otras damas dignas de mención pero estas dos parecen aglutinar a un mayor número de admiradores que resultan ser amistades de Mai y Minturno.

Sobre Giulia Gonzaga existe una larga literatura acerca de su personalidad y su influencia en muchos de los campos culturales de ese momento. ${ }^{63}$ Dama de gran reputación, fue uno de los posibles amores platónicos de Minturno, quien le dedicó una serie de sonetos al más puro estilo petrarquista. Es más, muchos otros autores del momento que cayeron enamorados de la belleza de dicha dama, también eran conocidos de Miguel Mai. Pongamos por ejemplo a Ludovico Ariosto, quien coincidió con Mai en los actos de la coronación imperial de Bolonia en $1530 .{ }^{64}$

60. Fosalba (2009: 85).

61. Ibid.

62. Toscazo (2001).
63. Destacamos por encima de todos a Oliva (1985).

64. Rizzi (1998). 
Debemos hacer un breve apunte artístico en relación a Giulia Gonzaga. Sobre ella ya hemos anunciado un pequeño detalle anteriormente: la posibilidad de que la escultura de la "Dama del armiño» del Museu Marès se correspondiera con su retrato. Lo cierto es que Giulia Gonzaga se encontraba en Nápoles por las mismas fechas en que la corte pasó unos meses allí; era muy célebre por entonces como dama culta que protegía a distinguidos autores, inmersa en su propio círculo de amistades culturales. Estando en Nápoles participó en algunas de las charlas organizadas por entonces. La posibilidad de que coincidiera con Mai hay que considerarla, como ya lo habían hecho en Roma unos años antes. Pero lo único seguro es la estrecha relación que a ambos unía con Juan de Valdés, hombre muy estimado en el Nápoles de aquel entonces. Ambos, Gonzaga y Mai, protegieron a Valdés ante las dificultades que conllevaba al conquense ser identificado con la heterodoxia. ${ }^{65}$

¿Es posible, entonces, identificar la escultura mencionada con dicha dama italiana? Sus retratos más conocidos responden a una iconografía muy parecida a la de la escultura (fig.5), aunque bien es cierto que siguiendo esta línea podríamos identificar en la pieza de alabastro a muchas otras damas del momento. Es más, en el inventario de bienes de Mai, escrito en 1546, se documenta una escultura con una descripción exacta de la misma pieza, sin añadir ninguna identificación con la Gonzaga. El único elemento de duda con base documental la proporciona el inventario de bienes de 1548, escrito dos ańos después de la muerte de Mai, en el que aparece documentado «un bulto de piedra llamado Julia». ${ }^{66}$ No parece suficiente para establecer la identidad de la pieza. Quizá debiéramos barajar la posibilidad de que, si realmente se trataba de un retrato de Giulia Gonzaga, se evitara su completa identificación a causa de su fama poco ortodoxa en cuestiones religiosas, lo que podía conllevar a sus propietarios problemas innecesarios; y esto significaría que su fama habría llegado a Barcelona y más concretamente, al notario y los escribientes que inventariaron la pieza. ${ }^{67}$ Ante todo, pues, prevalece la duda razonable; hay que considerar, eso sí, que Miguel Mai y Giulia Gonzaga mantuvieron algun tipo de relación a través del mundo del arte y la literatura, favorecida por episodios como los fastos de Nápoles.

La otra dama de la que debemos mencionar es María de Cardona. Descendiente de una de las principales familias de la nobleza catalana, formó parte de todo este entramado sociocultural, no solo como interlocutora, sino también como objeto de algunos de los escritos realizados por algunos de los poetas presentes en Nápoles, como es el caso de Minturno. ${ }^{68}$

65. Courcelles (2004). No hay que descartar la posibilidad que Mai conociese a la Gonzaga a través de su relación con los duques de Mantua.

66. Garriga (1996a).
67. Para un análisis de los retratos de Giulia Gonzaga, que podemos comparar con las noticias que ofrece De Rossi (2009), podemos consultar a Contini (2008: 218 y 242).

68. Fosalba (2009). 
Como decíamos, María de Cardona formaba parte de un núcleo familiar muy potente en los reinos de la Corona de Aragón. De hecho gracias a la red clientelar que tenían los Cardona se hace comprensible el ascenso de la familia de Miquel Mai en la administración real, pues estuvieron sirviendo al lado de los Cardona en varias ocasiones; por ejemplo, cuando Joan Mai (hermano de Miguel), fue secretario del obispo Pere de Cardona, protector a su vez de Miguel Mai en cuestiones devocionales, ya que ambos profesaban admiración por las ideas de Erasmo de Rotterdam. Por su parte, Miguel Mai estuvo al servicio de Ramon de Cardona, virrey de Nápoles, cuando el primero ocupó su cargo de Regente del Reino de Cerdeña, un cargo que en numerosas ocasiones suponía visitar al virrey napolitano. ${ }^{69}$

Es por ello que Miguel Mai debía ya conocer a María de Cardona cuando se encontraron en el viaje de vuelta de la campaña africana, contribuyendo también a que formara parte de ese núcleo nobiliario que participaba de las tertulias que vamos nombrando. La relación con Maria de Cardona no termina aquí, Minturno fue precisamente uno de esos poetas que escribió algún tipo de composición amorosa dedicada a dicha dama, ${ }^{70}$ como el mismo Garcilaso. ${ }^{71}$

Además de a María de Cardona, también es obligado citar a otra dama procedente de la nobleza catalana tan familiar a nuestro Miguel Mai. Se trata de Isabella Villamarino o de Vilamarí, descendiente de Bernat de Vilamarí, virrey de Nápoles a principios del siglo xvi. Isabella se encargó de la protección de algún personaje como Scipione Capece o Juan de Valdés, al tiempo que cultivó la amistad de otra dama insigne que hemos mencionado, Giulia Gonzaga. ${ }^{72}$ Estas damas y muchas otras aparecen en un texto que debió de circular casi el mismo tiempo que la estancia de corte en tierras italianas. Se trata del Amore prigionero de Mario di Leo, una obra que podemos encontrar entre los libros inventariados de la biblioteca de Miguel Mai, lo que vuelve a poner de manifiseto la importancia de las fechas pasadas en Nápoles y sus alrededores, tanto desde una perspectiva histórica como literaria. ${ }^{73}$

Con lo expuesto hasta aquí se ha pretendido añadir un apunte más a la contextualización de algunos de los personajes más destacados de la primera mitad del siglo XVI en la corte imperial. En ningún caso se ha pretendido fijar la figura de Miguel Mai como epicentro cultural de la misma corte, sino que el análisis del personaje se ha propuesto como punto de partida para analizar algunos episodios relevantes de la época que le tocó vivir.

69. Bellsolell (2011).

70. Fosalba (2009: 70 y ss.).

71. Morros (2008b) y Morros (2009).

72. Segarra (2001).

73. Acerca de algunos círculos literarios en Nápoles ya escribió Fosalba (2009); en comunica- ción privada, la misma investigadora me adelanta que hay algún otro foco de intercambio en el círculo de los hermanos Seripando, que hubo de influir muy notablemente en Garcilaso, aspecto sobre el que tiene un estudio en preparación. 


\section{Apéndice documental}

\section{CARTA No1. (Minturno, III, 6). ${ }^{74}$}

ALL'ECCENTISsimo S. Maio Vececancellere d'Aragona.

Quando era in Roma V.S. dove gia fu molti anni conmolta sua laude, e con grande honore àpo il Sommo Pontefice Ambasciadore de la Cesarea Maesta spesse volte caddi in pensiero di doverli scrivere, mosso dal grido di quel valore; il quale ho sempre havuto in somma riverenza. Ma ch'io non le scrivessi, non so se piu m'avuenne per l'oportuno tempo, il quale parendomi che tutto di mi s'offerisse, ne mai mancar mi dovesse, si di lungò si quell'hora di por mano alla penna, che prima intesi esser lei gionta in Hispagna, ch'io cominciassi ad apparecchiare la charta e l'inchiostro, o per la sua grandezza, che l'humilta mi spaventana; o per no se che di rustichetto e contadinesco rossore che venutomi nel viso, anchora che secondo il proverbio la lettera non arrosisca, pur timoroso è lento me ne facea. Et hora sentendo che nel Reale Cesariano consiglio ha chiaro et honorato luogo, via meno d'ardimento n'havrei, se per lo $\mathrm{S}$. Andrea Ardoino de la sua maravigliosa humanità fatto certissimo non fossi. Con questa difendendomi, da la sua grandezza, e scacciata la vergogna che m'offendea, e presa l'oportunità per li capelli, ho scritto à V.S. E perche on venga la lettera sola, come che la compagnia sia d'ornamenti ignuda, le mando con essa la canzone da confortare i Principi Christiani alla impresa contro à Turchi; la quale gia sono tre mesi ó quattro, che a Papa mandai, non ch'io sperassi dover si potesse, ma per fare chiara testimonianza del mio pietoso affetto. Mandola à V.S. non gia ch'io creda questa esser tale che piacerle debba: ma percio che udendo io delettarle mirabilmente il Toschano stile, mi si fa tenere per fermo, che al meno à grado le sia, per l'esser composta in rima italiana. Quello anchora per la sua vertú singulare mi si promette, che non mavverrà di questa canzone quel, che dalquanti versi Latini, i quali io mandai ad alcuni cavaliere di cotesta corte Imperiale, mavvenne. Concio sia cosa che anchora non mi si sia prestato ch'i n'habbia risposta. Fararmi gratia di tenermi nel numero de suoi servidori, e s'io conoscero i componimenti miei qualche di letto apportarle, persuadasi che quanto io scrivo, qualunche egli si sia, tutto sia suo. Piaccia al N. Signor Dio di prosperare et inalzare l'Eccellentissima sua persona quanto e quale ella disia.

Di Messina à VIII. de Decembre. M.D.XXXIIII.

\section{CARTA No2. (Minturno, III, 7).}

\section{AL MEDESIMO.}

Se buona pianta, come è l'anticho proverbio, buon frutto produce, e di buo-

74. La referencia entre paréntesis se refiere al libro tercero de Lettere di Meser Antonio Min- turno, $\mathrm{y}$ al orden que el propio Minturno le dio a su correspondencia. 
na vena escono chiari e dolci roscelletti, et in buon terreno herbe salutifere nascono, di persona scientiata et humana, che altro attender si dee, che atto gentile d'humanità. E nel vero veggendosi in V.S. ogni ricco ornamento di rara dottrina, et ogni lume di virtù con ogni leggiadria de lodevoli costumi, io non altro che cortesia ne posso, ne debbo aspettare. Il che piu manifestamente mi si dimostra hora che'l S. Andrea Ardoino m'ha scritto quanto benignamente, e con con che buona verso me volontà gli havete risposto intorno a quel, ch'io gia chiedeva. La onde mi sento esservi in obligo tanto piu, quanto riconosco oltre à meriti miei cio dalla benignità vostra venirmi. Ma prego V.S. che à si dolci nodi di benigne parole mi s'aggiungano i distati legami de gli effetti cortesi: e s'egli è vero esser d'animo libero e gentile, à colui volersi piu obligare, à cui sia molto tenuto; ben che le forze mie siano deboli à sostenere il peso di tanta gratia; pur credere vi si faccia non potermisi fare si grandine tanti benefici, che nell'animo mio piu non ne capa, come in quello, che d'esservi piu sempre obligato desidera. Concio sia cosa che non quel che puo e vale ciascuno, ma la volontà sia misura del cuore. E se l'altrui buon volere basta à persona larga e magnanima de la mia verso oi devotione contentarui debbitare senza guardare à cio, ch'io mi sia, avvenga che s'altri per me scrivesse, cio che la modestia à me vieta di scrivere, havrebbe quello per aventura ardimento di dire, ch'io sia tale, che voi d'haverui col vostro beneficio acquistata la mia servitù à pentirui non habbiate. Essendomi venuto à notitia quanto viscono amiche non pur le Latine Muse, ma le Toschane anchora, con l'altra mia lettera vi mandai quella canzone, che io feci per confortare alla impresa contro à Turchi, cosí à tutti i Prencipi Christiani, come spetialmente il Papa. Quantunque io sapessi che mandava Nottole ad Athena: percio que io sento i vostri componimenti nell'una et nell'altra favella esser molto appregiati. Ma facemene ardito la fama: perche odo non esser si mal poeta, le cui scritture volentiervo i non leggiate. Et hora fatto avvisato per l'Ardoino quanto havete commendati alquanti miei versetti, et alquante rime, ho ripreso ardire di mandarvi questa altra accompagnata da non so quanti sonetti. Se l'opera non è quale voi la vorreste, non me, percio ch'io non la tengo degna d'esser à voi mandata; ma voi stesso, prego incolpiate; che ogni compositione, qualunque ella sia, mostrate d'havere in pregio. In Latino non ho da mandarvi nuovo poema: percio che'l traducere da Greco mi tiene occupato. Ma di questa faticha vi farò parte. Concio sia ch'io habbita tra le cose da me tradotte il Convitto de sette savi da Plutarcho composto, et infin à qui da niuno altro, ch'io sappia, fatto Latino. Il quale tosto che siaa trascrito, il che si fara infra pochi giorni, di mandarvelo mi son disposto. Non dimeno perche non venga questa lettera senza versi Latini vi mando, ch'io scrissi della pace fatta tra Cesare et il Re di Francia all'hora, che'l Conte di Santa Severina di felice memoria era in Napoli di sua Maesta Luogotenente. Quando mi si prestarà tempo et otio da scrivere poeticamente, Il primo lavoro sia consecrato a V.S. à cui bascio la mano.

(sin lugar de origen ni fecha) 


\section{CARTA No3 (Minturno, III, 8).}

\section{AL MEDESIMO.}

Rallegromi assai meco stesso che non pur non trovo ingannata l'openione, che de l'humanità di V.S. mi s'era nella mente creata. Ma di gran lunga da la sua virtù la veggio avanzata: concio sia cosa che l'havermi si cortesemente risposto, e dimostrato oltre a'meriti miei una somma volontà, non possa venirmi altronde, che da una singulare et incredibile sua gentilezza. Rallegromi via piu con le Muse; le quali nell'Imperiali Palazzi hanno un si caro amico: che, se riguardiamo alla liberalità sua verso tutti gli spiriti gentili, e delle buone lettere studiosi, à tempi nostri è un nuovo Mecenate: se all'alto ingegno, et alla mirabile sua dottrina, pareggia chiunche de gli antichi nelli studi de l'eloquentia e del sapere piu di pregio e di fama ottenne. La onde quel che ella per sua cortesia di se mi scrisse; assai piu ragionevolmente à me è richiesto chi'o scriva à lei di me stesso; l'obligo mio esser doppio, et alla ineffabile sua benignità, che si benignamente prende à grado la mia servitù, et al Signor Andrea Ardoino, per lo cui mezzo nel numero de suoi servidori gia posto mi conosco. Il che à tanta gratia mi reco, a quanta non so se mai servo si reco la nuova libertà; $\mathrm{e}$ forse à maggiore. Percio che s'egli è vero, che tutti in qualunque stato serviamo, io tengo felicissimo quel servire, il cui giogo è piu soave, et il peso piu leggiero, che l'esserne libero è sciolto. Radoppiami poi quel lo obligo, quando con tante lode inalza i componimenti miei di quante non che me indegno riconosco; ma niunto de'piu famosi nel dire in questa età degno ne stimo. Concio sia cosa che lodato io da persona dignissima d'ogni loda, di questo suo cortese giudicio attendo quell'honore e quel grido àpo tutti gli altri, i quali verranno, che le scritture mie stesse, anchora che fossero, quali ella le tiene, darvi gia mai per se non porrieno. Perche con non pocho biasimo io stesso mi condannerei; se parte non le facessi di quelle cose, le quali mostra d'havere in pregio: percio che essendole io servidore non indegne d'esser lette da lei; ma per ubidire à suoi comandamenti, quali che elle si sieno, mandargliele poi che ella me le dimanda. E cosi fo hora, e sarò sempre per inanzi, tenendo a sommo favore, che da lei si leggano. Dirò il vero, io mi morrò, se l'honorato suo nome non sia nelle mie rime, e ne' versi celebrato: à cio che quanto ella vale nell'una e nell'altra nostra favella. Quanto è il senno, quanto è il valore, quante e quali sono l'altre sue vertú, si come per se hoggi à tutti è piu chiaro che'l sole, e fia, spero, in eterno: cosi per me no stia, che in testimonianza de la mia verso lei servitù, sempiterna memoria non ne rimanda. Il che hora mi si vieta dal non poter'intralasciare l'opera cominciata di fa Latine alquante cose de Plutarcho. Concio sia cosa, che questo pocho, che al presente gliene mando, sia nulla à quel che dirne vorrei. Stia prego V.S. sana.

(sin lugar de origen ni fecha)

CARTA No4 (Minturno, III, 9).

AL MEDESIMO.

Riconosco l'obligo in ch'io sono à la V.S. de l'honore e de la fama; che m'aquista non solamente per le sue lettere chiedendomi le vane et rozze mie compositioni, 
ma per lo mezzo del Duca mio Signore, com se fosser cose, le quali per ottennere le bisognasse l'opera altrui, e di tale, che mi comanda; ne bastasse ella stessa; che di me puo promettersi quel, che niuno altro potrebbe. E riconosco esser tanto questo obligo, che non pur non le farei mai tanto servigio, che in parte me ne sciogliessi, ma parole trovar non saprei, con le quali aguagliarlo potessi. La onde ben ch'io conosca le mie rime esser indegne di pervenire à gli orecchi suoi, non dimeno percio che me'l comanda, questi me si addietro le mandai alquanti soneti: li quali maravigliomi, che ricevuti non habbia: et hora con questa alquanti altri le mando. La indegnità de le quali rime, senza incolparne me, prego perdoni alla sua cortesia, che degna tanto honorarle. E se vedrò queste esserle à grado, le maderò poi il Panegyrico tante volte cittato dal gesualdo ne la Spositione del Petrarca. Attenda prego à star sana.

Di Philocastro à XX. di Marzo M.D.XXXIX.

CARTA No5 (Minturno, III, 10). AL MEDESIMO.

Quanto m'è grave che per quel che scrisse al Duca mio Sig. V.S. di negligentia e d'oblivione accusto m'habbia, tanto e piu mi diletta a l'esser da lei il mio dovuto ufficio richiesto, massimamente percio che non ha luogo in me quella colpa, la quale m'è data: $E$ in quel che mostra di desiderare le mie lettere e le compositioni, mi descopre de l'humanità su nativa un cortese e gentile affetto, à me nel vero gia manifesto, ma dolce pur sempre e difiato. Mentre in Napoli mi trovai, niuna oportunità di scrivele mi offerse, ch'io volontieri non la pligliassi; e per me manco, che non si cercasse d'haverne sovente. La onde in quel poco di tempo spesse volte le scrissi. Poi che tornai qui in Calavria, in luoghi deserti et abbandonati, e del tutto lontani dal camino del sole, qual via potea tenere da scriverle e tanto piu mal'agevolmente m'era, ritrovandosi il Duca in Sicilia. Puo ricordarsi che vivendo quel Vecere di Sicilia, che d'esser gia Re veramente fu degno. Percio che le mie lettere havean la via presta et apparecchiata, sovente venieno à visitarla. Et in quel tempo anchora col favore di quel Signore, e con la speranza d'acquistarmene piu àpo Cesare, nelle cui mani Dio ha posto il piu, et il piu bello de l'Europa, era intento à scrivere le cose di sua Maesta tal volta anchora spendendo qualche hora in isfogare in rima et in prosa quelle passioni che giusto amore, e quell'età nell'animo mi chiudeva. De le quali scritture, percio ch'io conosceva quelle esserle à grado, piu volte le feci parte. Hora toltemi queste cagioni, non ho migha da spiegare in charta, che fuori mandar si debba. Concio sia cosa che amor m'habbia lasciato, et io nol richiami: E morte m'habbia tolto l'aiuto di quel Prencipe, il quale io non posso senza lagrime nominare. E quella speranza ch'un tempo in me fioria di poter poetare col favore di Cesare, e di V.S. e del Signor Granvela del tutto sia secca. La onde io mi sono dato à piu gravi studi, e vivo à me stesso, et alle Muse, senza haver piu cura, che mi si presti, o mi si neghi l'aiuto di cesare, o il suo, o d'altrui. E comendo tal'hora lo studio d'alcuni, messo piu tosto in biasimare, che in lodare. 
Poi che tali sono i Prencipi di questa età, dirò il vero; mai non mi potè cader nell'animo di voler dir male; et hora se la mia natura il sostenesse, vorrei poter farlo. E chi non disiasse diventar Archilocho, et armar la rabbiosa lingua d'altro che d'i iambi, s'altro puo esser piggiore. Ma io mi sono dato a piu gravi studi, e nell'una e l'altra lingua m'apparecch'io asai libri di Theologia, e scrivo à lungo. Et havendo in animo di fare un poema grande de le cose sacre, ho voluto prima raccogliere in alquanti libri tutti li ammaestramenti, li quali dee servare il poeta. La onde nuovo componimento niuno havendo, le mando alquanti de'vecchi. Tra uali sono gli ultimi sonetti, i quali mi truovo haver composti, e quella opera, la quale V.S. in Napoli mi significò che desiderava il Panegyrico in laude d'amore tante volte allegato dal Gesualdo nel Petrarca, e da me quando cominciai ad haver barba composto. Riconosco l'opera esser di stile alquanto affettato, et havrei potuto emendarla, e farla migliore. Ma ho voluto che si come ella nacque ne'primi anni della mia gioventu, cosi riservi et habbia seco i segni et i vestigi impressi di quella età giovenile, se per inanzi avverrà ch'i scriva qualche cosetta breve, e da poterle si mandare, dove io conosca che le sia à grado d'inviargliele non manchero, e le basci le mani.

Di Philocastroà VII de Giugno M.D.XXXVIII.

\section{CARTA No6 (Minturno, III, 11).}

\section{AL MEDESIMO.}

S'io non havessi, Eccellentissimo Signor mio, chiaramente conosciuto da una parte quale e qunata sia la volontà di V.S. verso me, e quanto quelle poche gratie che Dio m'ha date à grado ke siano per lo suo maraviglioso amore versi li studiosi de le vertuti; e per l'ardentissimo suo desiderio d'honorar quelli, e di beneficiarli; Da l'altra quanto sia il suo valere, e quanto possa giovare, e far bene ad altrui: non havrei mai pensato di palesarle qual mercede io desidero che da sua Maesta m'impetri. E banch'io sappia comme tutte l'altre cose del mondo, cosi le facende anchora esser sottoposte à giri del cielo e del tempo, et haver ciascuna la sua stella, come dissero non pochi de savi, e la sua fortuna; e quella disaventura che in tutti gli scientiati, et in quelli, che si studiano d'acquiestar dottrina ha tropo piu luogo, che ne gli altri, apertamemte veggia che mi perseguita, come uno de coloro, non dirò che son chiari, ma che s'ingegnano di piacere alle Muse non dimeno s'io non avisassi piu poter la felice vertù de grandi, che la fortuna avversa de poverelli, non tornarei a pregarla, che mostri chiaro à tutto il mondo haver piu potuto il suo valere in farmi ottenere la gratia disiata, che la mia sventura in farlami negare. Ma perche mel promette sua cortesia, et il mi sa sperare, vorrei mi si prestasse haver degna maniera di poterle à parole al meno rendere quelle gratie, de le quali esserle tenuto mi conosco. Anchor ch'io non dubbiti che la sua liberalità non sosterrebbe d'essere in modo alcuno ringratiata, per non scemare de le divine su lode. De l'altro, di che supplicai V.S. per lo Duca mio Signor, ringratio e lodo senza fine la sua vertù, àpo la quale ha piu valuto al fine il giusto et il vero, che l'altrui favore. Mostrando poi d'haver tanto à grado 
le mie lettere, e le compositioni, e chiedendo con tanta humanità ch'io spesso gliene faccia parte; fa quel che è di suo gentilissimo costume, per favorire le cose de servidori, le quali giacendo in terra, e non possendosi da se levare ad alcun grado d'honore, con l'aurora favorevole del Padrone s'inalzano à sommo pregio. La onde per ubidirle cosi il farò, come il mi comanda, qual hora il tempo oportuno mi sen'offerirà: quantunque io maveggia, che cio ch'io scrivo, non è degno di tale e tanto lettore. Habbia cura di star sana.

Di Monteleone à X di Decembre. M.D.XXXIX.

\section{CARTA No7 (Minturno, III, 12).}

\section{AL MEDESIMO.}

Non picciola gratia m'èstato l'essere da V.S. si famigliarmente trattato, che riprendendomi di negligentia e di dementicanza et accusandomi di poca fede in attener l'empromesse, chiede ch'io le scriva. Percio che di se mi fa veder chiro quel ch'io sempre ho veduto, ma che sempre m'è piu caro, quanto piu mi si fa rivedere, una sua verso me incredibile benevolentia, et un ardentissimo desiderio d'haver mie lettere spesso. E per somma cortesia mi priega c'hio la faccia di me e del mio stato, e di tutte le mie bisogne avista, mostrandomi apertamente qual fu sempre, e qual è piu di giorno in giorno apparecchiata la sua volontà di farmi gratie. Se la cortesia sostenesse d'esser mai ringratiata (percio che il ringratiare scioglie in parte l'obligo: onde chi lei ringratia, par che scemi la sua vertù; la quale è non pur d'obligare, ma di tenere sempre obligato altrui) m'ingegnerei di renderle quelle gratie, de le quali io le sono tenuto; anchor ch'io non bastassi mai d'aguagliarne à parole una menoma particella. Ma non mi si torrà che io non dica la S.V. chiaramente have dimostrato, quanto adorni e faccia piu belle l'altre vertù la cortesia. Concio sia cosa che con lo'ngegno, con la scienza, col giudicio, col sapere, conn l'avvedimento, e con tant'altre eccellentie del suo nobilissimo intelleto, essendo ella ornamento de la Cesarea corte, e con gli atti cortesi illustri se stesso, et alla magnanimità di Cesare laude accresca, come unico rifugio e sostenimento de vertuosi. La onde posso meritevolmente gloriarmi, ch'io piaccia tanto à persona si valorosa, e di tanta autorità; che prestandosi largamente il suo favore ad ogni spirto gentile, de l'esserle si caro quel ch'io sono, benche sia poco o nulla, pur fede s'acquista ch'i sia qualche cosa. Di che le sarò eternamente obligato. Ma percio che parrebbe forse ad alcuno, ch'io fossi in quella colpa, de la qual m'accusa, s'io non me n'iscusassi, onde biasimato sarei d'essere ingrato, e di non haver ben conosciuto un'animo grande verso me si cortese e si largo; con questa di punto in punto lo isgannerei di si falsa credenza, se la sua vertù non mi promettesse, che per un'altra mia dal Duca mio Signore inviatale con non pocha parte de'miei componimenti, ha gia cangiata openione, e non piu m'incolpa. Ma ecco non le mancherà cagione di dannarmi, se'l benigno et avveduto suo giudicio non mi difende. Le parrà per avventura, che scritto havendomi di Barzellona à XII. di Febraio, io le devrei, gia sono piu mesi, haver risposto. Ma priego non 
sostenga mi si faccia torto, ne mi danne prima, che m'oda, che giustitia fia, che io porti la pena dell'altrui fallire. Saro io accusato del pigro e tardo venir de la sua lettera la quale o per altrui colpa, o per impedimento, ò per disaventura consumò nella via di giungere in Calavria piu di sei mesi. Piacesse à Dio, che le lettere havessero ale, o Cavalli, o Navi à loro posta, che'l volo, o il corso non fosse loro impedito. E perche meriterei biasimo di non haver saputo usare la sua benignità; s'io di me non le significassi particolarmente quel che saperne desidera, non tacerò che dopo la sua dipartita di Napoli, non molti mesi io stetti in quella città, che in Calavria con questi Signori me ne tornai. E trovandomi ingannato de la speranza posta da me nella Cesarea grandezza, e veggendo le mie fatiche non essere fatte degne d'honore alcuno, rivolsi la mente, et magnanimi et honorati fatti di Cesare ad altri studi. La onde mi vado apparecchiando all'anticha Theologia: de la quale ho raccolto alquanti libri Greci. E se pur le Muse mi constringessero à poetare, ho voluto prima informar me stesso de'loro ammaestramenti, scrivendo di cio, che bisogna al poeta per essere eccellente; la quale opera sarebbe gia compiuta, s'altre facende interrotta non me l'havessero. E percio che à tale studio mi son dato, ne questa età è si acconcia all'amoroso incendio, come la passata, poco in rima mi trovo havere gia scritto. Di che parte con questa le mando, con quella che'l fattore del Duca mio Signore le portò, il Panegyrico in lode d'amore, et alquanti sonetti le mandai. Altro no ho che de miei studi le scriva. Del mio stato che le scriverò in seno de povera e tranquilla fortuna mi godo. Poi che le Muse non hebbero potere, ne col vostro, ne con l'altrui favore d'impetrarmi tanto, che in Napoli riposata vita menar mi facesse. Dirò il vero, udendo ragionare di non so che liberalità novellamente usata da Cesare verso la vertù d'alcuni spiritti leggiadri, la speranza che'era spenta, mi si raccese; perch'io mi volsi, e dissi alle mie fatiche, che anchora di loro attendo il frutto. Questo ho voluto che sappia di me, havendomi comandato, ch'io di cio la faccia avisata. Hor V.S. conoscendo il mio bisogno, io sarei ingiurioso alla sua cortesia, se cosa alcuna le chiedessi. Da quella istessa mi si permette, che farà ogni opera di procacciarmi bene: eso che non gliene mancherà l'occasione, veggendo per buona ventura il Signor Don Luigi d'Abila, et il S. Conte di Fonte, et el S. Morano, prego nella gratia di quelli con l'autorità sua mi mantenga. Habbia cura di star sana.

Di Napoli à XV. d'Ottobre M.D.XL.

\section{CARTA No8 (Minturno, III, 13).}

\section{AL MEDESIMO.}

Se le mie lettere valesser tanto, quanto V.S. l'estima, troppo gran felicità sarebbe la mia. Ma percio che l'openione di tanta et tale persona chiara gloria m'acquista; coprendo con l'unbra del suo favore i difetti del mio ingegno, e col suo splendore ingannando gl'occhi de gli huomini che non veggiano l'oscuro del mio stile: et à ciascuno giova di credere cio, che laude gli apporta: io mi goderò di questa 
credenza, senza cercare d'haverne piu certezza: e porgo i piu devoti preghi ch'i possa alla singulare sua vertù, che mi mantenga in tal gratia àpo V.S. conoscendo io massimamente non essere merito alcuno in me, che cio prometer mi possa. Concio sia che tanti favori, con li quali di di in di m'accrescie piu obligo, tutti da la sua cortesia mi vengano, e quella supplico non le sia grave d'aggiungere à tanti legami di servitù, ne'quali mi stringe, quest'altro anchora M. Anibal Coccia Secretario Regio di Sicilia, et agente del S. Duca di Monteleone àpo sua Maesta sono passati alquanti mesi, che diede memoriale in corte à mio nome: $\mathrm{e}$ mi scrive essere stato ispedito con aspettativa, e rimesso alla consulta che si fara in Italia. Vorrei s'havesse à fare in Hispagna, accio che mi valesse l'opera sua presentiale, promessami non una volta. Ma supplico V.S. mi faccia gratia di quel favore che lontananza mi toglie di potermisi prestare con la disiata sua presentia, che mi si conceda con lettere, scrivendone à su Maesta, et al Signor di Granvela in mia raccomandatione. Diche tengo per fermo che seguirà il desiderato effetto. Delle cose pertenenti al S. Duca non mi fa motto, per non farmi parte, come scrive, di cio, che sappia di lite: forse pensando da litigi esser lontani li studi delle Muse. Ma nel vero non sene dilungano, quanto altri s'avisa: anzi mi pare che sien molto loro da presso, essendo si cara amica delle Muse Pallade; che è Dea de giudici, come quella, che prima ordinò i giudici in Athena, e diede à quelli il tribunale nell'Areopago; e tanto piu s'egli è vero, che la prima sapientia, secondo che n'ensegna Horatio, et io l'affermo nel mio Poeta, fu la Poesia, et ella radunò in città gli huomini, che prima sparsi per li campi e per li monti n’andavano; è diede loro le leggi: et i poeti governavano la repub. difendeano gli accusati, ponean fine à litigi. Ma forse parrà à V.S. che o il Signor Andrea Ardoino, o pur io non habbia servato fede. Perche havendole io promesso per lo mezzo di quello mandarle alcuna mia compositione, pottrebbe farle si credere che, o per colpa di liu, o per mia niuna infin'à qui da quel tempo n'habbia recevuta. Il che veramente è avvenuto non per diffetto de l'un di noi duo, ma per essermi io partito di Sicilia e di Calavria, e dilungato da lui troppo avanti, ch'i potuto havessi per quella via la promessa attenerle. Hora dopo l'essere ito peregrinando mi trovo in Napoli, e fo trascriverle il Panegyrico, e vedrò d'inviargliele per lo mezzo del Secretario Martyrano, s'egli mi prometterà di mandargliele per buona via; poi che non n'hebbe il primo essempio, che di Calavria gliene mandai. L'Ardoino non so come prometterle potuto habbia l'Academia: la quale perduta fu prima, che compiuta: percio che quella opera dame adombrata, quando havea ad esser dipinta de suoi colori, nella peste di questa città, che fo da XXVII. a XXIX. si perdè. Che se l'altre promesse di quello sono tali; veggia egli in qual maniera le possa adempire. Eramisi acceso nell'animo un desiderio ardente di mostrare quanto valse il Petrarca di dottrina et eloquentia, e quanto il Boccaccio, e come tutte le belle figure e maniere del parlare si trovino cosi in questa nostra, come nella Greca, e nella Latina favella. Ma con l'essersi perduto il dissegno, prima que si dipingesse, quel disio mi si spense. Ne mai piu mi s'è potuto raccendere, si perche la fatica era si lunga, che perduta una volta mi parea troppo duro e grave 
il ripigliarla, si perche questa lingua è venuta è va di giorno in giorno perdendo: la dove si creda che sarebbe ita avanzando. Concio sia cosa che li scientiati è li studiosi de le buone lettere havendo cominciato con multo studio à farla bella; quando poi si sono avveduti non essere loro avvenuto àpo i Prencipi quel pregio, che conseguir ne doveano, l'habbiano lasciata in potere de volgari: nel mezzo de quali ella era nata, e che per lei si veggiono dal mondo, oltre à meriti loro appregiati. La ond'io come uni de menomi, non dirò de li scentiati, ma certo de'desiderosi di scienza acquistare dilungato da quel camino, mi sono messo in questa via, per la quale veggio coloro andare, che piu di me sanno, e sono ben degni ch'io li debba, com'io possa il meglio, seguire. Ho voluto darle di cio ragione: accio che sappia che è avvenuto di quella opera, ch'è tante volte nella spositione del Petrarca allegata. E creda per certo V.S. conoscendo, quant'io le son servidore, che se quella vivesse, io non sarei stato si tardo à farnelo Signore, si come ha in Signoria quanto è in me, e quanto io vaglio, come che tutto ciò sia nulla o poco. E le baccio la mano.

Di Napoli à V· di Genaro M.D.XXXXI.

\section{CARTA No9 (Minturno, III, 14).}

\section{AL MEDESIMO.}

Poi che quanto io piu mi studio d'inalzare la gratia di V.S. riconoscendo da quella venirmi, che l'opere mie sieno fatte degne di qualche laude: tanto piu allojncontro l'humanità sua s'ingegna di porre in alto i meriti miei, ch'io tengo à nulla; ho pensato di non venir piu in questa contentione: Ma si come in ogni altra cosa, cosi in questa rimaner vinto, et inferiore. Percio che essendo io servidore; è ben ragione che del tutte io li ceda. Ma perche il beneficio apporta se non piu, certo non meno di laude à chi il fa, che d'utilità à quello che'l riceve; e cosi per far piu chiara la sua cortesia, come per rilevare con qualche bene il basso mio stato, non cesserò d'ufare il favore e l'aiuto tante volte, con tanta prontezza d'animo e cosi cortesi parole profertomi da V.S. avisandomi, che à lei fia tanto à grado di prestarlomi quanto à me di conseguirlo. Credo li ricorda che io per lo suo mezo supplicai Cesare mi facesse gratia di provedermi di quel che all'hora l'oportunità mie richiedevano. Ma conosciuto havendo si per quel che V.S. da prima me ne significo, e si per li effetti, che mal volentieri sua Maesta simil gratia concede, mi s'è fatto pensare che quella sarà piu spedita, et agevole via da impetrar mercede, che non toglie del proprio, ma quello da che tenere non si puo. E vorrei, parendo à lei, cio ritentare per quel camino, il qul cominciai à tenere, quando il Duca di Monteleone di gloriosa memoria era Vecere di Sicilia; anchora che per quello infin à qui non sia giunto al fine disiato. La onde con questa gliene mando il memoriale. E quanti prieghi posso maggiori, se prieghi mi ci bisognano, le porgo, non pur col favore, ma con l'opera faccia che tal gratia m'impetri. Concio sia ch'io non habbia fatto questa supplicatione con altra speranza, che con quella, la qualle ho messa tutta nell'humanità sua, 
e nella benevolentia, la quale, so che per sua vertù sopra i meriti miei mi porta. Ottenendo io questa mercede, havrò quella commodità, la quale hora mi manca, d'essercitare lo ingegno con la forza datami di sopra, in servigio di Christo e di sua Maesta. Percio che come Christiano mi debbo ingegnare d'indrizzare à Christo à guisa di vero mio fine, quanto io posso operare con la gratia che da lui mi viene; e come servo di sua Maesta, ho à servirla, quanto vgliono le picciole mie forze, con l'arte, nella quale io mi sono da primi anni essercitato. $\mathrm{Ne}$ l'uno ne l'altro, come sa, si puo ben fare da chi non e ben proveduto di tutto quel, ch'en cio gli fa di mistiere. Il provedermene è richiesto à sua Maesta, di che quanto io le sarò in obligo sempiterno, tanto merito n'havrà àpo Christo: Il quale è Signore di tutto; il che non avverrebbe, quando a mercede si havesse à spendere in mal'uso. Ma perche di cio scrivendo à V. Signoria, ho detto troppo, supplico non lo m’imputi d altro chi à gran fidanza, la quale mi pare havere di poter liberamente con lei ragionare. El le bacio le mani.

Di Napoli à II· d'Agosto M.D.XLI.

CARTA No10 (Minturno, III, 15). AL MEDESIMO.

S'io fossi stato Eccellentissimo S. mio, si tardo à far questo libbro, il quale hora mando à V.S. come sono stato ad inviagliele; non è da dubitare che quello sarebbe piu degno di darlesi à leggere. Percio che molti e moltianni sono che in pochi di m'usci di mano, qual venir potea da me in quella età giovenile. E ben che in questa piu matura habbia riconosciuto l'acerbo de l'opera, non però ho voluto addolcirlo. Concio sia cosa ch'io stimi in ogni opera doversi vedere i segni di quella età, nella quale sia composta; e quella esser bella, che col tempo si conforma. Ne meno di diletto havere ad apportare la varietà de lo stile, che nelle compositioni si trova secondo le diverse età, che quella de'modi, e de le figure del parlare; la quale è richiesta in una istessa scrittura. Ne per altro il Melarancio de li alberi fruttiferi è il piu pregiato, che per la diversità de pomi, la quale in lui d'ogni tempo appare: percio che quello quando ha i maturi, non lascia d'havere li acerbi. E ben si puo credere, che da le differenze non pur de l'ingegni humani, ma de gli anni ancora sien nate tante e si varie maniere di scrivere. Ne mi si dee negare, che la belleza de le cose non sia posta nella varietà. Concio sia che Dio per ornamento de l'universo, e per chiarezza del suo potere, e del suo sapere habbia voluto, non che tutte le nature esser fra loro diverse, ma niuna cosa particolare trovarsi non varia da l'altra: e certo la divina Essenza si unica e singulare, per esser piu bella di tre distinte persone s'adorna. Mosso da queste ragione, non ho voluto cangiar migha in questo libbro da quel ch'egli era da prima; ma qual fu da primi anni, tal gliele invio. Questo è il Panegyrico tante volte nominato dal mio Gesualdo nella sua spositione de le rime del Petrarca, e da V.S. chiesto, non una volta. Vorrei che fosse tale, che l'ardente desiderio ad empiergliene potesse. Ma qualunque egli si sia, la sua vertù mi promette, che in questo non guarderà nella 
qualità de l'opera, che per se nulla vale, ma nella volontà mia verso lei: che piu tosto ho tolto d'acquistar biasimo, manifestando l'ignorantia mia; che di non ubidire al disio di V.S. tenendola celata. De l'essere stato si tardo ad inviargliele, non voglio iscusarmi; ancor ch'io giustamente iscolpar me ne possa, per non haverne havuta la commodità piu per tempo: Ma paratissimo sono à patirne quella pena che V.S. vorrà darmene. E le baccio le mani.

Di napoli à XXV. di Giugno M.D.XLI.

\section{CARTA No11 (Minturno, III, 16).}

AL MEDESIMO.

S'io non m'havessi, Eccellentissimo Signor mio promesso de la volontà di V.S. verso me quanto d'un'ottimo e gratiosissimo patrone, premettermi posso, non le havrei si fidatamente raccomandata la mia supplicatione. Ma gratia singulare m'è stato l'haver conosciuto per una sua de III. del passato quella prontezza de lanimo suo verso me, la quale m'era piu chiara de la luce istessa. Supplicola, se suplicatione mi ci bisogna, mi conservi questa sua buona gratia: de la quale non attendo altro che cortesi e benigni affetti. Ringratio Dio Signor nostro, che'l consiglio de Fisici le habbia giovato à mitigare il dolor de la gamba. E sia pregato Apollo, à cui fu commesso da Giove l'esser capo de Poeti e de Fisici, che come l'enspira lo ingegno nelli studi de le scienze, così habbia cura da la sanità sua. De le mie cose non si puo dire, ch'io non mi ricordi di farle parte: percio che pochi di sono, che per lo mezzo di M.Aurelio, il quale è in casa del Secretario, le inviai il Panegyrico, et hora fo copiare un'altra opera da me chiamata Amore inamorato, per mandargliele. De la memoria che V.S. ha de le cose di questi miei Signori, le bacio le mani: E ben so che vede chiaro il torto, che si fa loro; et il buon merito che loro altri rende de benefici ricevuti. Che dirò de la lettera di cesare al Vecere di sicilia con tanto favore de l'aversario, e come dicono, con tanto pregiudicio de capitoli e de riti di quel regno infin à qui sempre da lei, e da li antecessori suoi servati, che spaventa chiunque l'ode o legge. Non dico che S. Maesta nol possa fare, volendo usare la libera et omnipotente sua potentia. Ma non so s'è di si giusto Prencipe, qual è Carlo, per favorire uno, derogare de li antichi privilegi in persona di tale, il quale ha perduto un'Avolo et un Padre in servigi di sua Maesta: E per fermo in servigi rari e notabili, Perdoni, supplico, all'humanità sua, s'io non dubito di parlare liberanente, scrivendo à V.S. la cui Eccellentissima persona sia pregato il N.S. Dio di conservare, e d'aumentare come e quanto desia.

Di Napoli à VI. di Maggio del XLII. 


\section{Bibliografía}

Addesso, C.A., Le Stanze del Fuscano sovra la Belleza di Napoli, Tesis doctoral inédita, Nápoles, 2005.

Álvarez, Mat T. - Mateos, A., «La biblioteca de Miguel Climent Gurrea, protonotario de la Corona de Aragón (1563)», Boletín del Museo e Instituto Camón Aznar, 65, Madrid, Museo Camón Aznar, (1996), 99-130.

Bataillon, M., Erasmo y España. Estudios sobre la historia espiritual del siglo XVI, Madrid, Fondo de Cultura Económica, 1983.

Batllori, M., "Humanisme i Erasmisme a Barcelona, 1524-1526)», De l'Humnaisme i de Remaixement. Obra completa 5, València, Edicions 3i4, (1995), 145-169.

Belda, C., «Sibilas virgilianas en el Renacimiento español: La Sibila de Cumas de El Salvador de Úbeda (Jaén)», Imafronte, 1, Murcia, Universidad de Murcia, (1985), 5-21.

Belenguer, E., La Corona de Aragón en la Monarquia hispánica. Del apogeo del siglo XV a la crisis del XVII, Barcelona, Península, 2001.

Bellsolell, J., Producció artística i consum domèstic: el mobiliari i l'abillament de la casa de Miquel Mai (c.1475-1546), Trabajo para la obtención del título de DEA en la Universitat de Girona, inédito, 2009.

—, «Notícies sobre Miquel Mai, el seu retrat i la ecoració artística del seu casal barceloní», Locus Amoenus, 10, Barcelona, Universitat Autònoma de Barcelona, (2009-1010), en prensa.

-, Miquel Mai (c.1480-1546). Art i cultura a la cort de Carles V, Tesis doctoral inédita, Girona, 2011.

Bodart, D.H., Tiziano e Federico II Gonzaga. Storia di un rapporto di committenza, Roma, Bulzoni Editori, 1998.

Caballero, F., Conquenses ilustres. Alonso y Juan de Valdés, Madrid, Oficina tipográfica del hospicio, 1875.

Carbonell, J., "Anotaciones inéditas sobre Virgilio de Antonio Agustín», Habis, 25, Sevilla, Universidad de Sevilla, (1994), 413-430.

Castiglione, B., El cortesano, Madrid, Cátedra, 2003.

Cátedra, P., Nobleza y lectura en tiempos de felipe II. La biblioteca de don Alonso Osorio Marqués de Astorga, Valladolid, Junta de Castilla y León, 2002.

Codoñer, C. - SIGNES, J. - DOMINGO, A., Biblioteca y espistolario de Hernán Núñez de Guzmán (El Pinciano). Una aproximación al humanismo espanol del siglo XVI, Madrid, CSIC, 2001.

Contini, R., "Ritratto di donna come Sant'Agata», Sebastiano del Piombo. 1485-1547, Roma, Federico Motta Editore, (2008), 218-219.

Courcelles, D., "Juan de Valdés à Naples (1534-1541). Courtisan, philologue et réformateur spirituel», Humanisme et église en France méridionale (Xve sièclemilieu du xvie siècle), Roma, École Française de Rome, (2004), 327-347. 
DE Rossi, A., «La dama con l'ermellino del Museu Frederic Marès di Barcellona: un ritrato inedito di Giulia Gonzaga Colonna», Vitelliana. Bolletino della Società Viadanese, Anno IV, Mantua, (2009).

Duran, E., "L'erasmisme als Països Catalans», Erasme i l'erasmisme, Tarragona, Universitat de Tarragona, (1986), 41-65.

Duran, E., «Antonio Agustín y su entorno familiar», Antonio Agustín between Renaissance and Counter-Reform, Londres, The Warburg Institute, (1993), 5-19. Duran, E., Estudis sobre cultura catalana al Renaixement, València, Edicions 3i4, 2004.

Duran, E. - Solervicens, J., Renaixement a la carta, Vic, Eumo, 1996.

Duran i Sanpere, A., "Miquel Mai, col-leccionista d'Art», Per a la història de l'art a Barcelona: glosses a documents dispersos, Barcelona, Institut d'Estudis Catalans, (1960), 93-116.

FEnzI, E., «Et havrà Barcellona il suo poeta. Benet Garret, il Cariteo», Quaderns d'Italià, 7, Barcelona, Universitat Autònoma de Barcelona, (2002), 117-140.

Flores Sellés, C., Epistolario de Antonio Agustín, Salamanca, Ediciones Universidad de Salamanca, 1980.

Fosalba, E., «Implicaciones teóricas del alegorismo autobiográfico en la égloga III de Gracilaso. Estancia en Nápoles», Studia Aurea, 3, Girona-Barcelona, (2009), 39-104.

García Martínez, S., «El erasmismo en la Corona de Aragón en el siglo XVI», Erasmus in Hispani. Vives in Belgio, Lovaina, Aedibus Peeters, (1986), 215-290. Garriga, J., «Escultor desconegut del taller de Mino da Fiesole. Bust d'August», Lèpoca dels genis. Renaixement i Barroc, Barcelona-Girona, Ajuntament de Barcelona i Ajuntament de Girona, (1988a), 346-349.

—, «Escultor desconegut del taller de la cartoixa de Pavia (?). Bust de Domicià», Lèpoca dels genis. Renaixement i Barroc, Barcelona-Girona, Ajuntament de Barcelona i Ajuntament de Girona, (1988b), 350-352.

—, «Escultor desconegut. Bust d'Higiea (?) o de la Prudència (?)», Leèpoca dels genis. Renaixement $i$ Barroc, Barcelona-Girona, Ajuntament de Barcelona i Ajuntament de Girona, (1988c), 353-356.

—, «Escultor desconegut. Bust de Miquel Mai», L’època dels genis. Renaixement i Barroc, Barcelona-Girona, Ajuntament de Barcelona i Ajuntament de Girona, (1988d), 357-361.

—, «Relleus renaixentistes amb bustos de Cèsars i Virtuts de la col-leccció de Miquel Mai», D'Art, 15, Barcelona, Universitat de Barcelona, (1989), 135-166. —, "Martí Díez de Liatzasolo (doc.1527 - + 1583) (?), Priscil-la o Dama de l'ermini», Catàleg d'escultura i pintura dels segles XVI, XVII $i$ XVIII: època del Renaixement i Barroc, Barcelona, Museu Frederic Marès-Ajuntament de Barcelona, (1996a), 217-219.

—, «232. Anònim. Bust femení. República romana (?)», Catàleg d'escultura $i$ pintura dels segles XVI, XVII $i$ XVIII: època del Renaixement $i$ Barroc, Barcelona, Museu Frederic Marès-Ajuntament de Barcelona, (1996b), 276-277. 
Gonzalo, J.L., Regia Bibliotheca. El libro en la corte española de Carlos V, 2 vols., Mérida, Editora Regional de Extremadura, 2005.

Guilleumas, R, «Sobre les edicions gramaticals erasmianes impreses a Barcelona els segles XVI i XVII", Homenaje a Jaime Vicens Vives, 2 vols., Barcelona, Universitat de Barcelona, (1965-1967), 213-230.

Hernando Sánchez, C.J., «El Virrey Pedro de Toledo y la entrada de Carlos V en Nápoles», Investigaciones históricas: Época moderna y contemporánea, 7, Valladolid, Universidad de Valladolid, (1987), 7-16.

Huizinga, J., El otoño de la Edad Media, Madrid, Alianza, 2003.

KRISTELLER, P.O., Iter italicum. A finding list of uncatalogued or incompletely catalogued humanistic manuscripts of the Renaissance in italian and other libraries, II Italy, Orvieto to Volterra, vatican City, Londres, The Warburg Institute, 1977.

-, Iter italicum. A finding list of uncatalogued or incompletely catalogued humanistic manuscripts of the Renaissance in italian and other libraries, IV, Great Britain, Spain, Londres, The Warburg Institute, 1989.

López, L., «Notas sobre las amistades italianas de Garcilaso: un nuevo manuscrito de Pietro Bembo», Homenaje a Eugenio Asensio, Madrid, Gredos, (1988), 291-309.

Losada, A., Epistolaio de Juan Ginés de Sepúlveda (selección), Madrid, Ediciones Cultura Hispánica del Centro Iberoamericano de Cooperación, 1979.

Madurell, J.Ma - Rubió i Balaguer, J., Documentos para la historia de la imprenta y la librería en Barcelona (1474-1553), Barcelona, Gremio de Editores y Libreros y Maestros Impresores, 1955.

Maffei, S., "La villa di Poggioreale e la Duchesca di Alfonso II d'Aragona in una descizione di Paolo Giovio Modulli dell'elogio e tradizione anticha», Annali della Scuolo normale superiore di Pisa, IV-1/2, Pisa, Scuola Normale Superiore di Pisa, (1996), 161-182.

Martínez Millán, M., La Corte de Carlos V, 5 vols., Madrid, Sociedad Estatal para la conmemoración de los Centenarios de Felipe II y Carlos V, 2000.

Menor, M., «Llevar Lechuzas a Atenas no vale un óbolo», Paremia, 18, Madrid, (2009), 217-224.

Minturno, A.S., Lettere di meser Antonio Minturno, Vineggia, 1549.

-, Arte poética (Edición y traducción de Ma del Carmen Bobes Naves), 2 vols., Madrid, Arco Libros, 2009.

Moles, P., Família i política al segle XVI català, Barcelona, Rafael Dalmau, 1990. Molza, F.M., Elegiae et alia, Torino, Res, 1999.

Morros, B., «La canción IV de Garcilaso como un infierno de amor: de Garci Sánchez de Badajoz y el Cariteo a Bernardo Tasso», Criticón, 80, Toulouse, Université de Toulouse II-Le Mirail: Institut d'Etudes Hispaniques, (2000), 19-47. —, "Fuentes, fechas, orden y sentido del libro I de las Obras de Boscán», Revista de Filologia Española, 88-1 (enero-junio), Madrid, CSIC, (2008a), 89-123.

—, "Garcilaso y Propercio: a propósito del soneto XXIV», Voz y Letra, XIX-1, Madrid, Arco Libros, (2008b), 101-111. 
—, «La muerte de Isabel Freyre y el amor napolitano de Garcilaso. Para una cronología de sus églogas y de otros poemas", Criticón, 105, Toulouse, Université de Toulouse II-Le Mirail: Institut d'Etudes Hispaniques, (2009), 5-35.

Morte, C., «La colección de pinturas, tapices, dibujos, estampas y esculturas de Miguel Climent Gurrea, protonotario del Consejo Supremo de Aragón y otros inventarios del siglo xvI», Boletín del Museo e Instituto Camón Aznar, 65, Madrid, Museo Camón Aznar, (1996), 131-164.

Oliva, M., Giulia Gonzaga Colonna tra Rinascimento e Controriforma, Milán, Mursia, 1985.

PARISI, I., «Un informatore del Cattolico: Benet Garret detto il cariteo», $\mathrm{La} C o$ rona d'Aragona ai tempi di Alfonso il Magnanimo: I modelli politico-istituzionali, la circolazione degli uomini, delle merci, gli influssi sulla società e sul costume, Nápoles, Paparo, (2002), vol.II, 1553-1562.

Querol, E., Estudis sobre cultura literària a Tortosa a l'Edat moderna, Barcelona, Publicacions de l'Abadia de Montserrat, 2006.

Rizzi, M., Antonio Sebastiani Minturno e Giovanni Andrea Gesualdo, Roma, Caramanica editore, 1998.

Rubió i Balaguer, J., "Humanisme i Renaixement», La Corona de Aragón en el siglo XVI (VIII Congreso de historia de la Corona de Aragón, València, 1-8 d'octubre de 1967), València, (1973), 9-36.

Sans i Travé, J.Ma (ed.), Dietaris de la Generalitat de Catalunya, Barcelona, Generalitat de Catalunya, 2004.

Segarra, I., "A propòsit d'una lectura sobre Benet Garret Il Cariteo (14501514) (Giovanni Parenti)", Faventia, 20-1, Bellaterra, Universitat Autònoma de Barcelona, (1998), 85-94.

—, «Humanismo y Reforma en la corte renacentista de Isabel de Vilamarí: Escipión Capece y sus lectoras», Quaderns d'italià, 6, Bellaterra, Universitat Autònoma de Barcelona, (2001), 123-135.

-, Endimió retornat:estudi sobre Benet Garret, Il Cariteo, Badalona, Omicron, 2007.

Serassi, P., Poesie di Francesco Maria Molza colla vita dell'autore, Milán, Società Tipografica de'Classici Italiani, 1808.

TORre, A., Documentos sobre relaciones internacionales de los Reyes Católicos, Barcelona, CSIC, 1949-1966.

Toscano, T., "Le vice-roi Granvelle et les hommes de lettres napolitans», Les Granvelle et l'Tlaie au XVIe siècle: le mécénat d'une familie (Acctes du Colloque international organisé par la Section d'Italien de l'Université de Franche-Comté, Besançon, 2-4 octobre, Besançon, Éditions Cêtre, (1992), 225-251.

-, "Carlo V nelle delizie aragonesi di Poggio Reale. Un accademia poetica di nobili napoletani in un raro opuscolo a stampa del 1536, Critica letteraria, XXII-83, Nápoles, (1994), 279-307.

-, «Le muse e i Colossi: apogeo e tramonto dell'umanesimo politico napoletano nel trionfo di Carlo V (1535)», Carlos Vy la quiebra del humanismo político 
en Europa (1530-1558), Madrid, Sociedad Estatal para la conmemoración de los centenarios de Felipe II y Carlos V, vol.III, (2001), 301-309.

VEGA, MaJ., El secreto artificio. Qualits sonorum, maronolatría y tradición pontanian en la poética del Renacimiento, Madrid, CSIC, 1992.

VILÀ, L., «Virgilio y la construcción simbólica del poder en el Renacimineto», Propaladia, 1, Barcelona-Girona, 2007.

Voltes Bou, P., Cartas del emperador Carlos I a la ciudad de Barcelona, Barcelona, Universidad de Barcelona, 1958.

Yeguas, J., «Miguel Mai embajador en Roma(1528-1533): erasmismo y mecenazgo", Roma y España. Un crisol de la cultura europea en la Edad Moderna, 2 vols., Madrid, SEACEX, (2007), 297-321. 